\title{
EXPLORING ENTREPRENEURIAL COACHING AS A GENDERED PHENOMENON WITHIN BUSINESS INCUBATORS
}

\author{
by \\ Mariah Maxheimer \\ BSc, University of Illinois at Urbana-Champaign, 2017 \\ A Thesis \\ presented to Ryerson University \\ in partial fulfillment of \\ the requirements for the degree of \\ Master of Science in Management \\ in the program of \\ Master of Science in Management
}

Toronto, Ontario, Canada, 2020

(C) Mariah Maxheimer, 2020 


\section{Author's Declaration}

I hereby declare that I am the sole author of this thesis. This is a true copy of the thesis, including any required final revisions, as accepted by my examiners. I authorize Ryerson University to lend this thesis to other institutions or individuals for the purpose of scholarly research. I further authorize Ryerson University to reproduce this thesis by photocopying or by other means, in total or in part, at the request of other institutions or individuals for the purpose of scholarly research. I understand that my thesis may be made electronically available to the public. 


\author{
Abstract \\ Master of Science in Management, 2020 \\ Mariah Maxheimer \\ Master of Science in Management Program \\ Ryerson University
}

Exploring Entrepreneurial Coaching as a Gendered Phenomenon within Business Incubators

Business incubators are organizations that promote and support entrepreneurial activity through services such as entrepreneurial coaching. However, how coaching impacts entrepreneurs is not well understood, particularly from a gendered perspective. It is essential to understand this gap because women are underrepresented in the field of entrepreneurship. Gender stereotypes create barriers that portray females as being less capable entrepreneurs. Therefore, women must overcome challenges that their male counterparts do not. The emergent model from this qualitative study of six female entrepreneurs, five male entrepreneurs and four coaches suggests three dimensions of coaching (venture support, emotional support, gender sensitivity) that benefit entrepreneurs. Insights into the differences between the coaching needs of men and women entrepreneurs were obtained by drawing on entrepreneurial self-efficacy to explain the relationship between the dimensions of coaching and entrepreneurial outcomes. The findings suggest implications for future research, incubation management, and public policy. 


\section{Acknowledgements}

To my thesis supervisor, Dr. Charlene Nicholls-Nixon, I would like to thank you for both accepting and guiding me throughout my graduate education. The value I have gained has far surpassed my expectations for this program because you gave me the push I needed to reach my true potential. You have been there every step of the way to challenge and encourage me, and I am truly grateful.

I would also like to acknowledge the individuals who participated in this study because, without your time and effort, this thesis would not have been possible. Lastly, I want to thank my thesis committee members, Dave Valliere, Wendy Cukier, and Andre Laplume, as well as the graduate program administrator, Anna Shevchenko, for helping me through the final stages of the completion of my degree. 


\section{Dedication}

This thesis is dedicated first to my family, particularly my parents Autumn and Leon Maxheimer, who have loved and supported me my entire life. You have helped open the doors that created this opportunity for me to pursue a graduate degree and provided me with the best thing parents can; a solid platform that I can use to build myself a better life.

This thesis is also dedicated to my partner, JJ Tang, for the immutable care and assistance you have given me. No one knows better than you what goes on behind the scenes, and I am so blessed to have someone to pick up the pieces when I am broken. You have given me the strength to persevere and maintain my sanity through this daunting task.

Thank you all, not only for the financial support but also for the emotional support that has allowed me to flourish in my personal and professional life. I am eternally grateful for the unconditional love I have received from all of you! I love you and honestly couldn't have done this without you. 


\section{Table of Contents}

AUTHOR'S DECLARATION ................................................................................................... ii

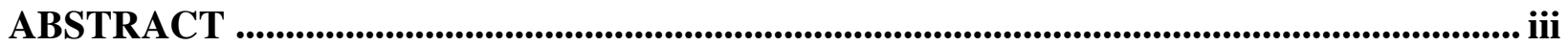

ACKNOWLEDGEMENTS …...............................................................................................

DEDICATION ....................................................................................................................................

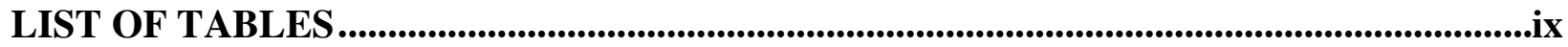

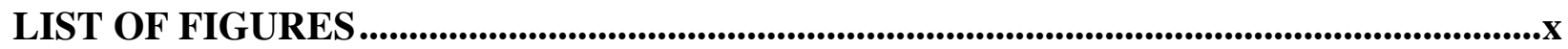

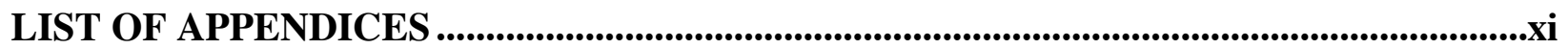

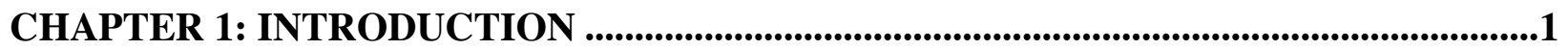

CHAPTER 2: LITERATURE REVIEW .................................................................................4

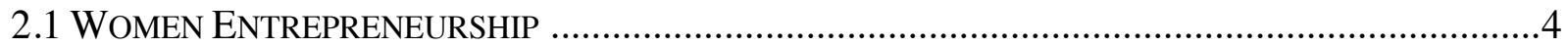

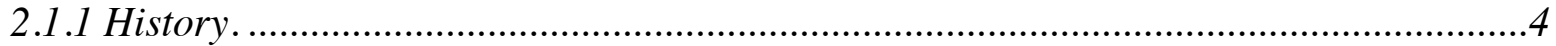

2.2 DISTINCTIONS BETWEEN WOMEN AND MEN ENTREPRENEURS ...............................................5

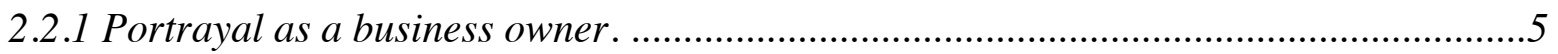

2.2.2 Venture performance .......................................................................................6

2.2.3 Management styles and strategies .......................................................................

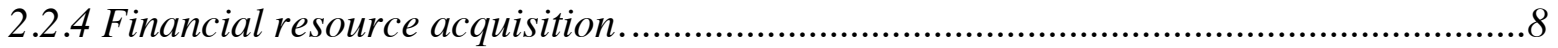

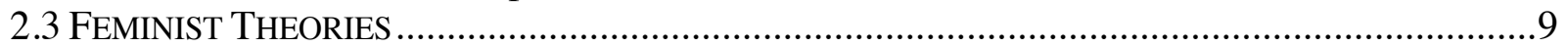

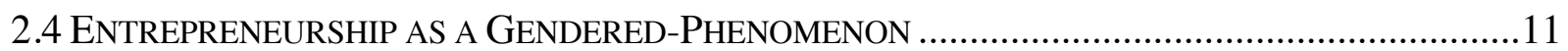

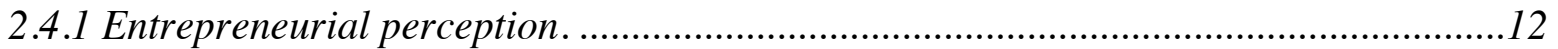

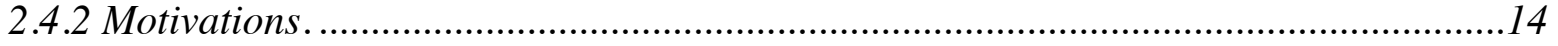

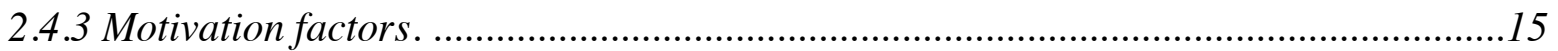

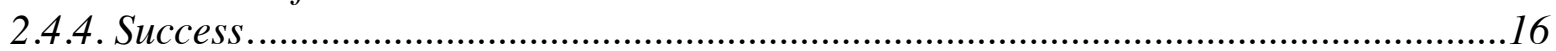

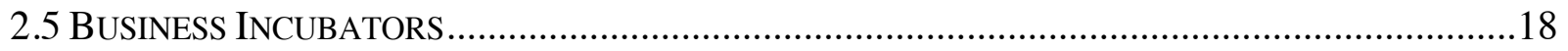

2.5.1 Business incubators in entrepreneurial ecosystems................................................. 18

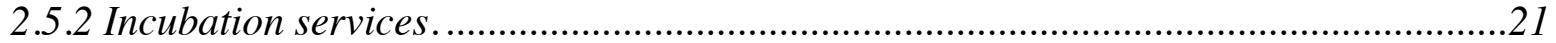

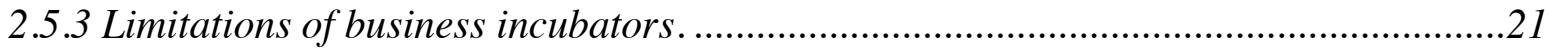

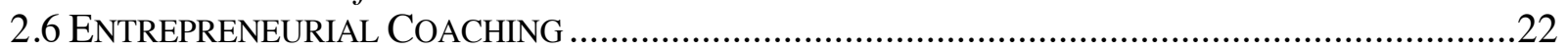

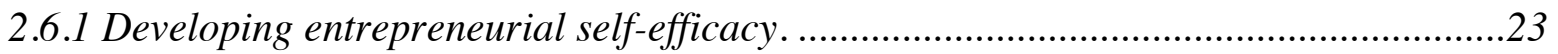

2.6.1a Pathways for developing ESE. .........................................................................24

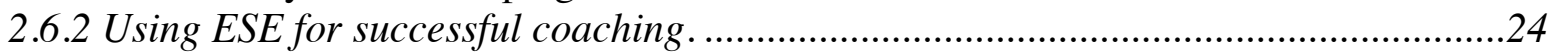

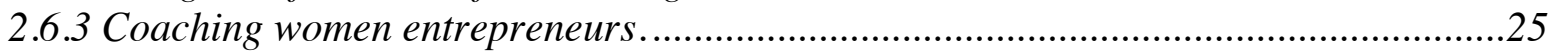

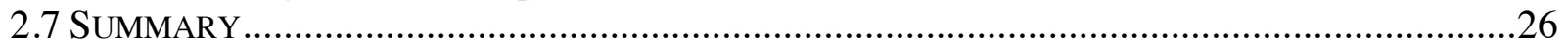

CHAPTER 3: METHODOLOGY ........................................................................................28

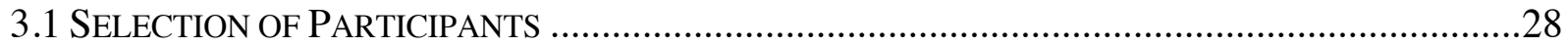

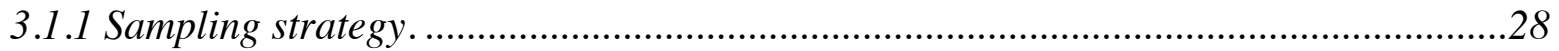

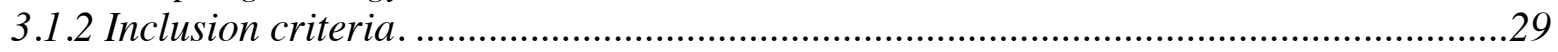

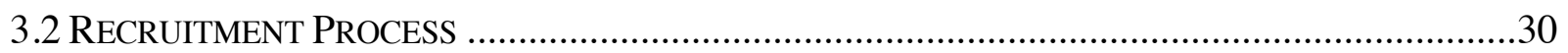

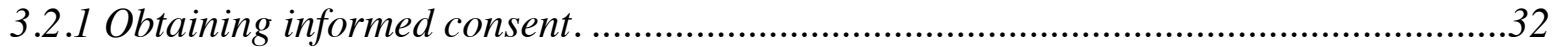

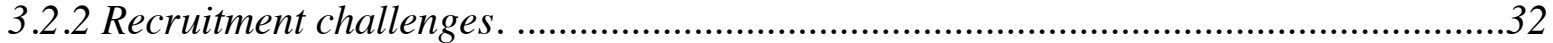




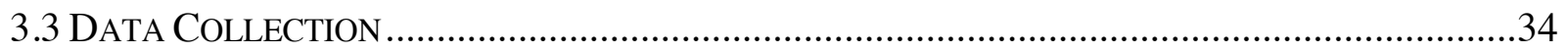

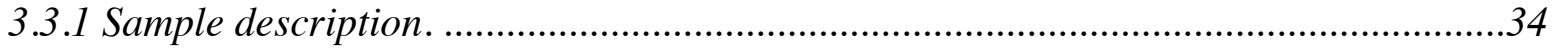

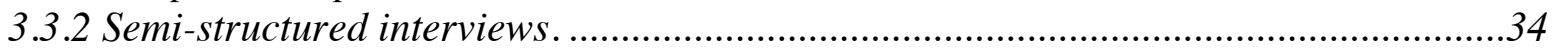

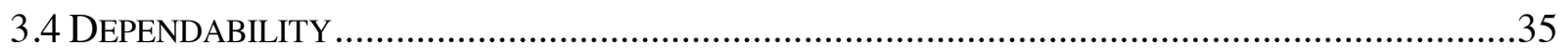

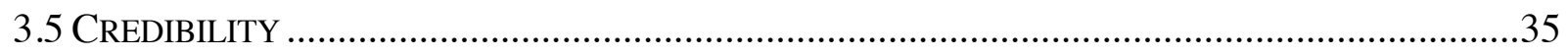

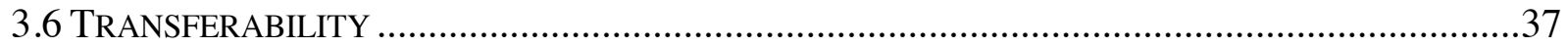

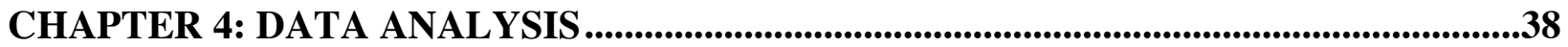

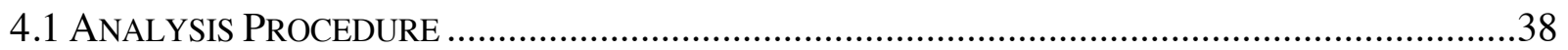

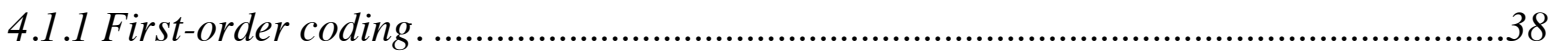

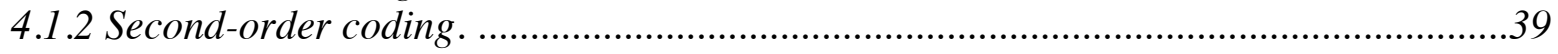

4.1.3 Grounded theory development. .............................................................................43

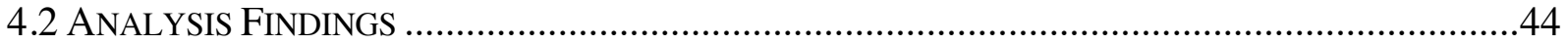

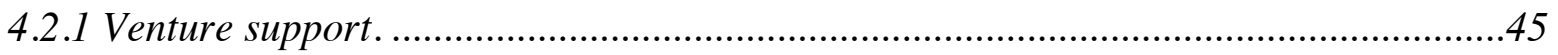

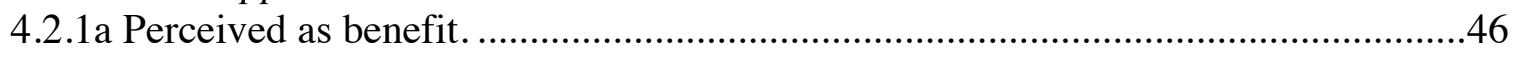

4.2.1b Perceived needs for improvement. ....................................................................

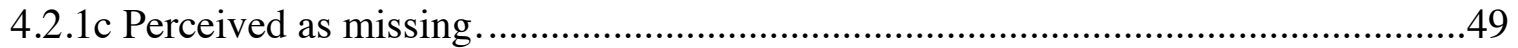

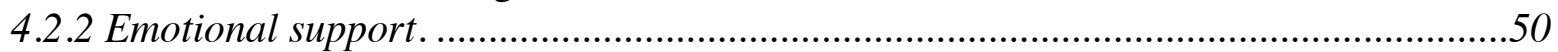

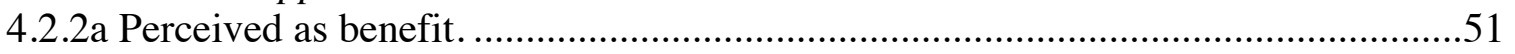

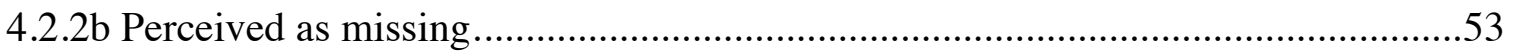

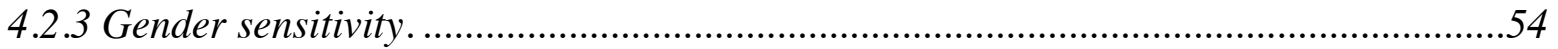

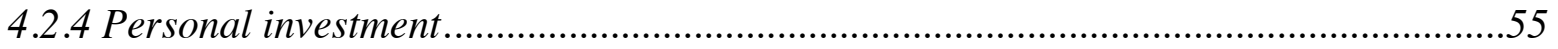

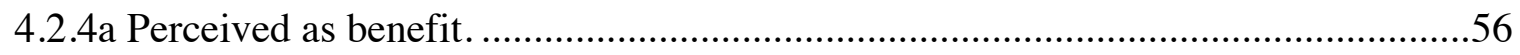

4.2.4b Perceived needs for improvement. ......................................................................56

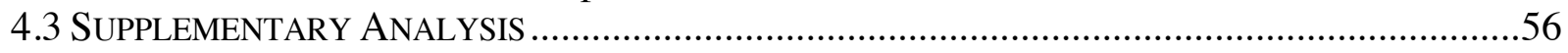

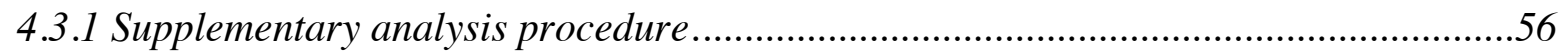

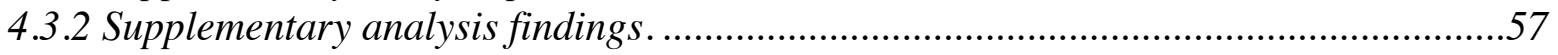

CHAPTER 5: DISCUSSION .........................................................................................................59

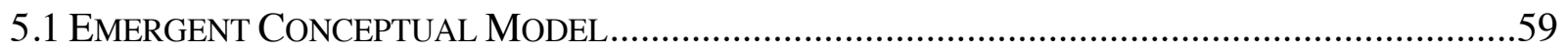

5.2 COACHING DIMENSIONS ………………………….................................................61

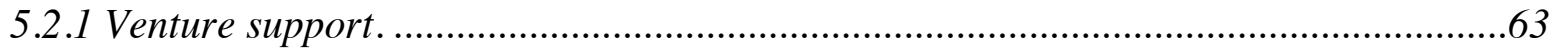

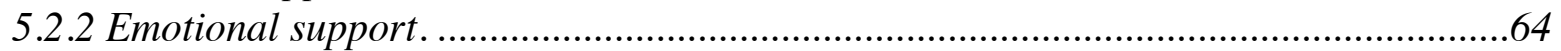

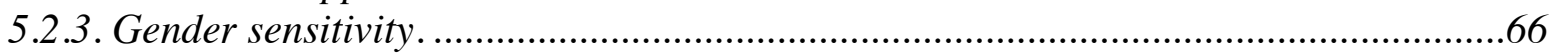

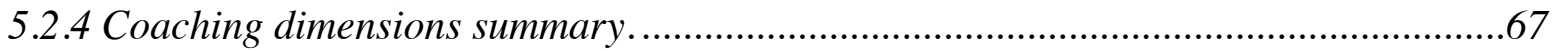

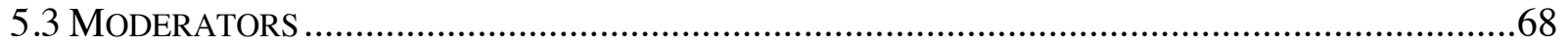

5.3.1 Personal investment of coach ............................................................................6

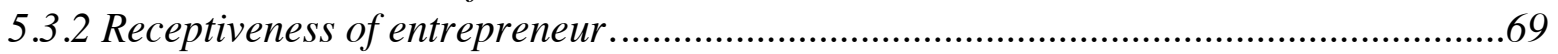

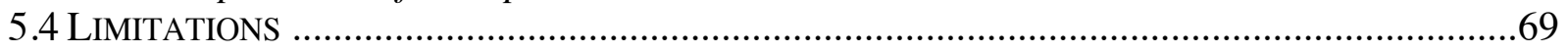

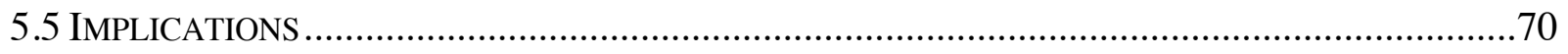

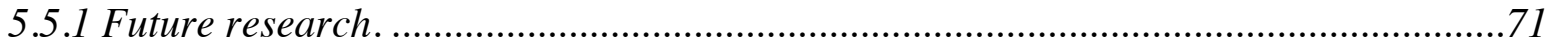

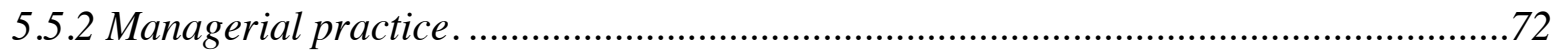

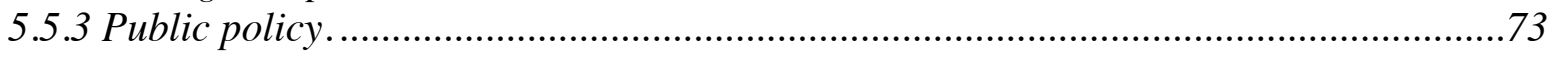

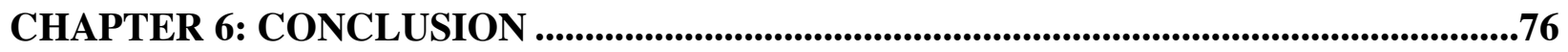

APPENDIX A: DIFFERENCES OF MEN AND WOMEN ENTREPRENEURS IN 
APPENDIX B: INTERVIEW GUIDE FOR ENTREPRENEURS ..........................................79

APPENDIX C: SUPPLEMENTARY ANALYSIS OF COACHES .............................................80

APPENDIX D: INTERVIEW GUIDE FOR COACHES ...............................................................87

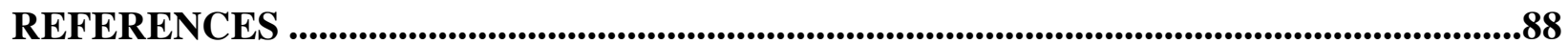




\section{List of Tables}

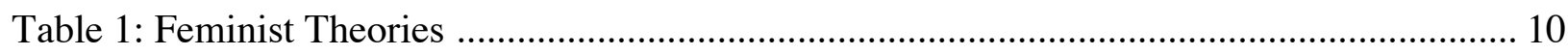

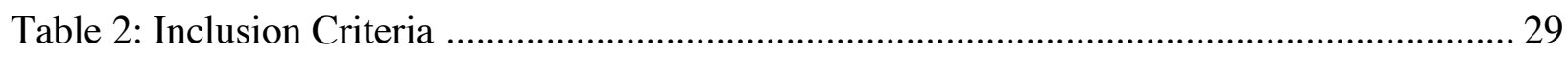

Table 3: Description of the Entrepreneurs' Background ...................................................... 34

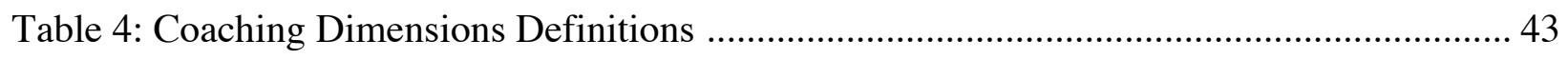

Table 5: Total Participant Counts per Dimension ................................................................ 45

Table 6: Venture Support Participant Count ...................................................................... 45

Table 7: Emotional Support Participant Count ............................................................... 51

Table 8: Description of Coaches' Background ............................................................... 81

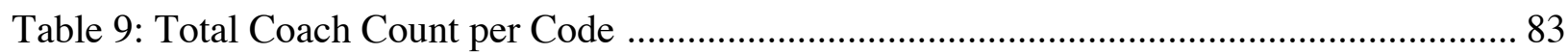




\section{List of Figures}

Figure 1: Flowchart of Recruitment Protocol ................................................................... 31

Figure 2: Data Collection and Analysis Timeline .............................................................. 33

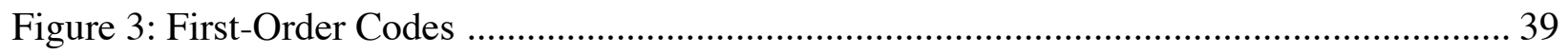

Figure 4: Visual Representation of Second-Order Coding Process ...................................... 42

Figure 5: Conceptual Model Linking Gender, Coaching Dimensions, and Entrepreneurial

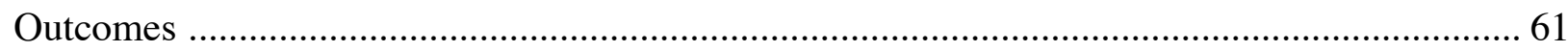




\section{List of Appendices}

Appendix A: Differences of Men and Women Entrepreneurs in Literature ............................. 77

Appendix B: Interview Guide for Entrepreneurs ......................................................... 79

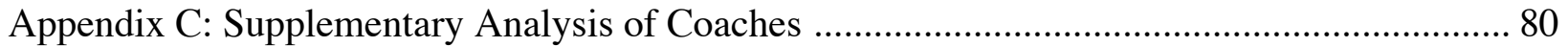

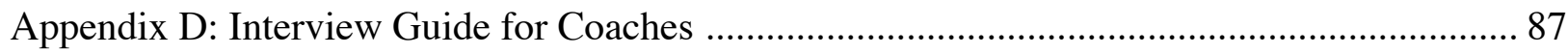




\section{Chapter 1: Introduction}

Entrepreneurship plays an integral role in economic growth and development by creating new goods and services, increasing employment opportunities, and improving productivity ("Budget Plan," 2018). Canada has some of the highest rates of entrepreneurial activity in the world (Hughes, 2017b), with almost three million people being self-employed in 2018 (Grekou, Li, \& Liu, 2018). However, entrepreneurship is a gendered phenomenon, meaning entrepreneurial activity is impacted by social constructs related to gender, specifically being dominated by males (Brush, Edelman, Manolova, \& Welter, 2018; Gupta, Weiland, \& Turban, 2019; Jennings \& Brush, 2013).

In this context, gender is defined as an individual's characteristics related to being masculine or feminine, while sex is the biological properties an individual has that make a man or woman (Brush, Edelman, Manolova, \& Welter, 2018). 'Gender' will be used as opposed to 'sex' for this thesis because the focus of the research is to observe similarities and differences between the characteristics and perceptions of individuals. It is recognized that there are additional genders identified, but for simplicity and the scope of this thesis, the focus will be only on two genders, men and women. Terms such as men/women and male/female will be used interchangeably to indicate the gender of participants.

Only $15.7 \%$ of businesses in Canada are solely owned by females, while over $64.6 \%$ are solely owned by males (Grekou et al., 2018). The discrepancy between female and male entrepreneurs is particularly prominent in STEM (science, technology, engineering, and mathematics) fields. Only $13 \%$ of women-owned businesses are within STEM fields (Simpson, 2018), while the rest fall under service industries, such as education, entertainment, or healthcare (Grekou et al., 2018). Due to the nature of these industries, female-led businesses have lower 
performance in sales, employment, and profits compared to their male counterparts (Grekou et al., 2018; Hughes, 2017b). Women entrepreneurs also face additional barriers to start and maintain entrepreneurial activity. Societal pressure impacts women more significantly in their life choices, particularly in the forms of gender bias or familial roles (Brush et al., 2018; PwC, 2018).

The Canadian government has recognized that female entrepreneurs are essential for making social and economic contributions, particularly to their families and broader communities (Hughes, 2017b). Therefore, as of 2018, they have implemented the "Women Entrepreneurship Strategy,” a \$1.4 billion plan, to help finance, support, train, and develop female entrepreneurs ("Budget Plan," 2018). One particular service they will be aiding is providing tailored support and coaching specifically for the needs of female entrepreneurs through boot camps and business incubators.

Business incubators are organizations that provide services and support to entrepreneurs to help develop and scale their start-up ventures. They are highly beneficial for start-up growth, but there is a lack of research on how the services impact both men and women entrepreneurs. Effective coaching services would seem to be particularly important for female entrepreneurs to develop entrepreneurial skills and grow their ventures because of the unique challenges they face.

Prior research has focused primarily on examining how male and female entrepreneurs differ, but not on the factors that work to help develop female entrepreneurs and their businesses specifically. It is essential to explore whether gender matters as a source of variation in entrepreneurial activity and behaviour. Therefore, the proposed research question is as follows: 
How does entrepreneurial coaching enable or constrain female entrepreneurs in their pursuit of new business opportunities?

What aspects of entrepreneurial coaching are the most or least helpful for the development of female entrepreneurs and their new ventures?

Are these aspects the same for male entrepreneurs?

This study will build on prior research by providing empirical evidence through semi-structured interviews with entrepreneurs and entrepreneurial coaches in BIs to understand how to make more inclusive coaching services. The findings of this study are important not only for entrepreneurs, but also for the government, policymakers, and program managers (Hughes, 2017b). Promoting female entrepreneurs and improving their performance also fosters gender equality and economic empowerment (Grekou et al., 2018). However, without understanding the most effective services, the money used to help female entrepreneurs will be wasted.

This thesis is divided into six chapters. The first chapter has introduced the problem and outlined the research questions. The second chapter will review the prior literature on female entrepreneurship, business incubation, and entrepreneurial coaching. The third chapter will describe the methodology of the research, including the selection of participants, data collection, and data analysis. The fourth chapter will present the findings from the data collected. The fifth chapter will discuss the limitations of the study, future research, and both managerial and public policy implications of the findings. The sixth chapter will conclude the thesis. 


\section{Chapter 2: Literature Review}

This section explores three fields of literature; women's entrepreneurship, business incubation, and entrepreneurial coaching. The purpose of investigating all three literature streams was to understand the nuances of female entrepreneurs and the avenues by which they can gain entrepreneurial support. The literature review will explain the history and key themes of each literature stream, then will readdress the research question in relation to the literature in a summary at the end.

\subsection{Women Entrepreneurship}

\subsubsection{History.}

The term 'entrepreneur' originated in the twelfth century initially meaning to do something or to undertake (Carlsson et al., 2013), but has since evolved to incorporate an economic role (Kirzner, 1997; Schumpeter, 1934). With this evolution, entrepreneurship has transformed from a subfield within many disciplines into its own unique field of study (Carlsson et al., 2013). Today, entrepreneurship can be defined as an economic function performed by an individual to bring future goods and services to existence through detecting, evaluating, and exploiting a viable opportunity (Hoskisson, Covin, Volberda, \& Johnson, 2011; Shane \& Venkataraman, 2000).

As the scholarly field of entrepreneurship has developed, some key questions have been derived: “(1) why, when, and how opportunities for goods/services come into existence; (2) why, when, and how some people and not others discover and exploit these opportunities; (3) why, when, and how different modes of action are used to exploit entrepreneurial opportunities" (Shane \& Venkataraman, 2000, p. 218) 
Through the investigation of these questions, gender has been identified as an important consideration in explaining the pursuit of entrepreneurial opportunities and outcomes. In this context, gender is defined as an individual's characteristics related to being masculine or feminine, while sex is the biological properties an individual has that makes them male or female (Brush et al., 2018). Particularly in the past 15 years, there has been an increase in gendered studies of entrepreneurship literature (Cabrera \& Mauricio, 2017), which has created a distinction between men and women entrepreneurs (Foss, Henry, Ahl, \& Mikalsen, 2018).

Throughout the past 30 years, gendered studies of entrepreneurship have transformed from primarily descriptive, explanatory work with unsophisticated methodology into using gender to inform and develop conceptual frameworks (Foss et al., 2018; Henry, Foss, \& Ahl, 2016). Approximately $90 \%$ of gendered studies prior to the early $21^{\text {st }}$ century used a quantitative methodology to compare male and female entrepreneurs (Henry et al., 2016). Today, the capacity of quantitative studies has decreased but continues to trump the number of qualitative studies performed in the field. These quantitative studies have helped build the foundation for the domain of women's entrepreneurship through unveiling four key areas of interest used to create a distinction between men and women entrepreneurs. These include the portrayal as a business owner, firm performance, access to finance, and management practices (Jennings \& Brush, 2013).

\subsection{Distinctions Between Women and Men Entrepreneurs}

\subsubsection{Portrayal as a business owner.}

Between the 1980s and 1990s, research primarily used quantitative comparative studies, including questionnaires and established statistical tests, to explore the differences and similarities between men and women entrepreneurs (Henry et al., 2016; Stevenson, 1990). It was 
found that overall, women are less likely to be self-employed (Hughes, 1999; Robinson \& Sexton, 1994) and less likely to be business owners or managers (Brush, 1998; Holmquist, 1997).

This phenomenon was found to be partially attributed to the portrayal of entrepreneurs within popular media and prior academic literature at the time. Both knowledge hubs promoted men as being more suitable entrepreneurs and did not include women entrepreneurs as their own distinct group (Baker, Aldrish, \& Liou, 1997).

\subsubsection{Venture performance.}

Between the 1990s to the early 2000s, research shifted its focus to quantitatively assess the performance of ventures ran by male vs. female entrepreneurs. Most of the performance metrics used were standard economic indicators that presented that women have inferior firm performance to men (Jennings \& Brush, 2013). On average, women have smaller businesses with lower employment levels (Cliff, 1998; Fischer, Reuber, \& Dyke, 1993; Orser \& Hogarth-Scott, 2002), lower total revenue (Alsos, Isaksen, \& Ljunggren, 2006; Rosa, Carter, \& Hamilton, 1996), lower total profits (Bosma, van Praag, Thurik, \& de Wit, 2004; Collins-Dodd, Gordon, \& Smart, 2004; Watson \& Robinson, 2003), and grow at slower rates (Cooper, Gimeno-Gascon, \& Woo, 1994; Riding \& Swift, 1990).

However, the majority of literature up until this time period took a gender as a variable (GAV) approach, which highlights the presence of women entrepreneurs, but lacks a comprehensive understanding of the effects that male-dominated occupational and social structures have on women (Foss et al., 2018). The GAV approach views men and women as equals and believes that by providing equivalent resources and opportunities, both genders can achieve similar levels of success. Consequently, there were no major findings in the differences 
between the male and female entrepreneurs, and it was concluded that women are subordinate to men because they have not properly adapted to their environment (Birley, 1989; Stevenson, 1986). Therefore, women are less likely to engage in entrepreneurial activity (Stevenson, 1990).

It is unsurprising that the performance indicators used in these instances were biased. These metrics align with male-specific measuring instruments, which lack an explicitly feminine approach (Ahl, 2006; Stevenson, 1990). Additionally, literature found that on average women entrepreneurs were equally as content with their success as their male counterparts (Cooper \& Artz, 1995; Powell \& Eddleston, 2008) and that using relative measurements to compare different sized ventures would present more positive results for women entrepreneurs (Watson, 2002).

\subsubsection{Management styles and strategies.}

Around the same time that performance became a focus, management practices also started to be assessed. The information about management styles and strategies was collected predominantly through quantitative surveys and secondary data to provide more explanatory work on start-up processes. There was a specific focus on defining the 'profile' of female entrepreneurs by describing their traits (Henry et al., 2016), such as the female-dominant business sectors, demographics, and personality types (i.e. Rosa et al., 1996; Shabbir \& DiGregorio, 1996).

It was found that women dominated sectors such as personal services and retail but were under-represented in fields like business services, manufacturing, and exporting (Allen, Elam, Langowitz, \& Dean, 2008; Orser, Riding, \& Manley, 2006). Also, women were more likely to run a home-based business (Collins-Dodd et al., 2004; Edwards \& Field-Henry, 2002) and pursue a social venture than men (Meyskens, Brush, \& Allen, 2011). 
Although some differences were found within the types of businesses owned, most literature concluded that the management and organization styles of male- vs. female-led businesses typically used a mix of both feminine and masculine approaches, and were primarily the same (Bird \& Brush, 2002; Brush, 1992). These results were also found in large scale studies (i.e. Chaganti \& Parasuraman, 1996; Cliff, Langton, \& Aldrich, 2005). Unfortunately, due to the large spread use of the GAV approach, broad assumptions about gender were often made that avoided contextual factors that could further explain the phenomenon of women entrepreneurs (Henry et al., 2016). This led to the overarching conclusion that women were to blame for their entrepreneurial failures.

\subsubsection{Financial resource acquisition.}

Entry into the $21^{\text {st }}$ century sparked the exploration of additional external factors, such as cultural influence, motivation, and finance. By the late 2000 s to early 2010 s, data was collected largely through surveys with more in-depth statistical testing (Henry et al., 2016). The geographical focus also expanded beyond the dominant regions of North America, the United Kingdom, and Australia. The major findings indicated that women not only launched their firms with lower initial funding (Carter, Brush, Greene, Gatewood, \& Hart, 2003; Carter et al., 2003; Fairlie \& Robb, 2009) but also operated with less finance (Alsos et al., 2006; Collins-Dodd et al., 2004).

It was also found that women were less likely to utilize external financial services, such as seeking angel investment (Becker-Blease \& Sohl, 2007) or venture capitalists (Coleman \& Robb, 2012). Before the year 2000, the percentage of women using angel investments was less than $9 \%$ of the total and less than $4 \%$ of venture capitalists. Of the small percentage receiving 
external finances, women were given less capital than male-led businesses and were significantly less likely to IPO (Greene, Brush, Hart, \& Saparito, 2001).

\subsection{Feminist Theories}

Since the expansion of the domain of women's entrepreneurship, there was also a significant increase in the use of qualitative approaches like interviews or ethnography (i.e. Susan Marlow, 2002). This pushed the limits of the definition of gender, which caused several theories to have risen in popularity, aside from the traditional GAV approach. In particular, the adoption of the 'gender as an influence' approach began to take precedence as it takes into account the social implications of gender (Foss et al., 2018; Henry et al., 2016).

Through the development of the 'gender as an influence' approach, two distinct feminist theories have emerged; feminist standpoint theory (FST) and post-structural feminism (PSF). FST, like the GAV approach, links gender and sex, but views women as being different from men because women have unique experiences due to the natural oppression within social systems, such as division of labour and unequal democratic rights (Calas \& Smircich, 1996; Gilligan, 1982; Harding, 1987).

PSF takes a divergent path by separating the meaning of 'gender' and 'sex' because it assumes that gender discrimination stems from social and cultural structures rather than from sex (Lene Foss, 2010; Hooks, 2000). Therefore, gender is defined as an individual's characteristics that relate to masculine or feminine traits. In contrast, sex became defined as the biological properties that make an individual a male or female (Brush et al., 2018). See Table 1 for an overview of feminist theories.

These new feminist theories incorporate social constructs associated with gender, such as expected work roles or differences in feminine vs. masculine traits, which has changed how it is 
conceptualized. This allowed for more large scale, longitudinal quantitative analysis that

expanding into new countries and extended beyond the basic comparison of men and women (i.e.

Hsu, Shinnar, \& Powell, 2014; Lewis, 2015).

Table 1: Feminist Theories

\begin{tabular}{|c|c|c|c|c|c|}
\hline $\begin{array}{c}\text { Feminist } \\
\text { Theory }\end{array}$ & View of Gender & Research Focus & Suggestions & $\begin{array}{l}\text { Appearance } \\
\text { into journals }\end{array}$ & Examples \\
\hline $\begin{array}{l}\text { Feminist } \\
\text { Empiricism } \\
\text { (GAV) }\end{array}$ & $\begin{array}{l}\text { Gender }=\text { Sex } \\
\text { Women and men } \\
\text { are the same. }\end{array}$ & $\begin{array}{c}\text { Make women and } \\
\text { their conditions } \\
\text { visible. }\end{array}$ & $\begin{array}{l}\text { Providing } \\
\text { equal } \\
\text { opportunity } \\
\text { and access to } \\
\text { resources }\end{array}$ & $1980 \mathrm{~s}$ & $\begin{array}{c}\text { (Anna, } \\
\text { Chandler, } \\
\text { Jansen, \& } \\
\text { Mero, 2000; } \\
\text { Kalleberg \& } \\
\text { Leicht, 1991; } \\
\text { Wicker \& } \\
\text { King, 1989) }\end{array}$ \\
\hline $\begin{array}{c}\text { Feminist } \\
\text { Standpoint } \\
\text { Theory (FST) }\end{array}$ & $\begin{array}{c}\text { Gender }=\text { Sex } \\
\text { Women are } \\
\text { different from men. }\end{array}$ & $\begin{array}{l}\text { Make women's } \\
\text { unique } \\
\text { perspectives from } \\
\text { oppression and } \\
\text { contributions } \\
\text { visible. }\end{array}$ & $\begin{array}{l}\text { Changing } \\
\text { social } \\
\text { structures }\end{array}$ & $1990 \mathrm{~s}$ & $\begin{array}{c}\text { (Bird \& } \\
\text { Brush, 2002; } \\
\text { Black, 1989; } \\
\text { Brush, 1992; } \\
\text { Fischer et al., } \\
\text { 1993; } \\
\text { Gilligan, } \\
\text { 1982) }\end{array}$ \\
\hline $\begin{array}{l}\text { Post- } \\
\text { Structural } \\
\text { Feminism } \\
\text { (PSF) }\end{array}$ & $\begin{array}{l}\text { Gender is socially } \\
\text { constructed through } \\
\text { history, geography, } \\
\text { and culture, causing } \\
\text { variation in } \\
\text { masculinity or } \\
\text { femininity. Sex is a } \\
\text { set biological } \\
\text { principle making } \\
\text { one male or female. }\end{array}$ & $\begin{array}{c}\text { Make gendered } \\
\text { discriminatory } \\
\text { practices visible. }\end{array}$ & $\begin{array}{c}\text { Changing } \\
\text { discrimination }\end{array}$ & $2000 \mathrm{~s}$ & $\begin{array}{l}\text { (Hooks, } \\
\text { 2000; } \\
\text { Neergaard, } \\
\text { Frederiksen, } \\
\text { \& Marlow, } \\
\text { 2011; } \\
\text { Nilsson, } \\
\text { 1997; Foss, } \\
\text { 2010) }\end{array}$ \\
\hline
\end{tabular}

Although there has been a clear shift from the GAV to gender as an influence approach, unfortunately, the research in women's entrepreneurship is still limited in the methodological approaches that have been taken and cannot match the level of sophistication of other similar disciplines. As research continues to adopt a gender as an influence approach, the data collection 
needs to include more qualitative methodologies to provide a strong theoretical framework and examples that help truly explain the phenomenon of women entrepreneurs (Henry et al., 2016; Stevenson, 1990).

\subsection{Entrepreneurship as a Gendered-Phenomenon}

Through these modern approaches, literature has found that entrepreneurship is not gender-neutral and instead is a gendered phenomenon (Brush et al., 2018; Gupta et al., 2019; Jennings \& Brush, 2013; S. Marlow \& McAdam, 2012). This means entrepreneurial activity is impacted by the social constructs around gender characteristics, related to both behaviour and roles associated with being male or female (Jennings \& Brush, 2013).

Dating back to the 1980s, Eagly developed the 'social role theory,' which parallels the assumptions made by modern feminist theories and aids in the understanding of the gendered phenomenon. Social role theory suggests that the beliefs about a group within society (particularly men vs. women) originate from experiencing the traditional roles and behaviours performed by the group members, which causes an association of those traits with that group (Archer, 1996; Eagly, 1987, 1997).

All societies have underlying expectations of characteristics that men and women possess, like their cognitive abilities or physical characteristics, that allow for them to fulfill their most productive gender-typical work roles (Eagly, 1987, 1997). In other words, social role theory shapes expectations of career paths for men and women that are reinforced by behaviour overtime.

Additionally, gender roles that have risen from the division of labour between genders link males with promoting agentic behaviour and females with promoting communal behaviour (Gupta et al., 2019). Agency includes traits such as independence, competence, and 
instrumentality, while communion relates to warmth, concern for others, and nurturance (Kite, Deaux, \& Haines, 2008) For example, the expectation that women are more compassionate explains why fields like teaching and social work are female-dominated. Historically, this has created gender stereotypes supporting males as paid employees and females as being homemakers (Archer, 1996).

Therefore, social role theory explains that since the average description of an entrepreneur reflects predominantly masculine traits, society associates male gender stereotypes with entrepreneurship. Consequently, non-traditional men and women interested in becoming entrepreneurs are negatively impacted (Gupta et al., 2019).

Overall, throughout the history of women's entrepreneurship research, there has been a clear shift from the GAV approach to the gender as an influence approach that has shaped the understanding and importance of gender vs. sex (Foss et al., 2018; Henry et al., 2016). Through additional literature referencing social role theory, the field has begun to carve out an explanation as to why women are underrepresented within entrepreneurship. Specifically, four domains that explore entrepreneurship as a gendered phenomenon have been identified as entrepreneurial perception, motivation, motivation factors, and success.

\subsubsection{Entrepreneurial perception.}

Literature has shown that women perceive fewer market opportunities than men (Kelley, Brush, Greene, \& Litovsky, 2011). Only 39\% of women within mature economies have identified entrepreneurial opportunities in their environment. Additionally, the women who do perceive opportunities only identify $90 \%$ of what men recognize (Kelley et al., 2017). This differing perception of one's environment is affiliated with how individuals view themselves and their capability to start their own business. 
Coinciding with opportunity perception, the capability perceptions of women are also lower within mature economies. This contrasts with the higher levels of education that women gain within these economies. $84 \%$ of women entrepreneurs in North American have a college degree (Kelley et al., 2017), which is higher than the number of male entrepreneurs (Minniti \& Arenius, 2003). Therefore, it can be inferred that many women do not think they are capable of being an entrepreneur, and out of the ones who do, they are very likely to have a college education or higher. Literature has shown a positive relationship between educational attainment and business ownership of women (Meunier, Krylova, \& Ramalho, 2017). However, higher education does not contribute to the preparation of women to become entrepreneurs, nor does it improve their confidence in business creation (Minniti \& Arenius, 2003).

Overall, these perceptions are tied to the social constructs created within cultures that associate women with household and familial roles (Fletcher, 2006). These constructs naturally shape women from a young age to tailor their personal ambitions to fill their expected position in society (Babcock, Laschever, Gelfand, \& Small, 2003) and define themselves through functions affiliated with "motherhood" (Jennings \& McDougald, 2007).

Therefore, women's entrepreneurial activity is embedded within families, not only because the motivations and decision to become an entrepreneur are reflective of familial needs, but the impacts of the processes and outcomes of the ventures are as well (Jennings \& Brush, 2013). Women's employment choice is more sensitive to the local environment than men because they are heavily impacted by regulations on childbearing and flexibility to accommodate family responsibilities (Minniti, 2010). The term "mompreneur" has become a colloquial term used to describe the average women business owner balancing her work with her household 
duties. It is a perfect example of how society expects women to meet their domestic demands in addition to having economic participation (Byrne, Farroum, \& Garcia, 2019).

\subsubsection{Motivations.}

The choice for someone to become an entrepreneur is motivated through two sources; necessity vs. opportunity (Jennings \& Brush, 2013). Necessity driven entrepreneurship is when one starts a business because they have few or no other employment options for them to support themselves and their families (Schermerhorn, Bachrach, \& Wright, 2018). Opportunity based entrepreneurship is where an opportunity in a market is acted upon, although there may be alternative options in the workforce. Entrepreneurs can be directly motivated through a single source or a combination of the two, depending on their external environment (Jennings \& Brush, 2013).

On average, women entrepreneurs are $20 \%$ more likely to have necessity motives than men. To interpret, women feel less obliged to start their own business unless there is a strong need (Kelley et al., 2017). However, this percentage varies due to the economic development level of each country. For example, in regions such as Sub-Saharan Africa with low economic development, $36 \%$ of women entrepreneurs cite necessity motives, but in North America with more mature economies, it is as low as $13 \%$ (Kelley et al., 2017).

Women entrepreneurs who are necessity driven are often more profitable than opportunity based because it is their way to ensure financial security for their families (Buttner \& Moore, 1997; Jennings \& Brush, 2013). Particularly within underdeveloped and transitioning economies, women entrepreneurs are propelled by necessity due to their need for survival (Jennings \& Brush, 2013). This could include but is not limited to seeking nutritional, educational, or health benefits for themselves and their families (Minniti, 2010). In contrast, 
women in developed countries who are necessity motivated have been found to become frustrated with the lack of career advancement opportunities, or the glass ceiling effect, forcing them to transition into entrepreneurship (Buttner \& Moore, 1997).

Although necessity drives many women, opportunity based motivation is the dominant reason for becoming an entrepreneur among both genders. There are over 1.5 times as many women entrepreneurs in less developed economies, and 3.5 times as many women entrepreneurs in developed economies that are opportunity-driven instead of necessity based (Kelley et al., 2017). However, the greater the economic development, the lower the total entrepreneurial activity. It can be inferred that with more mature economies, the "need" for entrepreneurship declines (Kelley et al., 2017).

\subsubsection{Motivation factors.}

In addition to the two main motivations, two distinct motivational factors can also act independently or in conjunction to attract people to become entrepreneurs; push vs. pull factors. Although these factors impact both male and female entrepreneurs, their importance is viewed differently by each gender (Brush, 1990). Pull factors are related to the positive recognition of a market opportunity and are the main motivation for one to participate in entrepreneurial activity. They include desiring independence, income potential, and self-fulfilment (Jennings \& Brush, 2013).

In contrast, push factors are associated with negative displacement and dissatisfaction, motivating a change in employment (Brush, 1990; Shapero \& Sokol, 1982). It is comprised of income strain, job dissatisfaction (i.e. glass ceiling), and the need for flexibility for family concerns (Jennings \& Brush, 2013). Research has established that women have greater relational and social motivations than men (Manolova, Brush, Edelman, \& Shaver, 2012). Therefore, 
women are more greatly impacted by push factors, most often due to their concern for familial and household duties (Brush, de Bruin, \& Welter, 2009; Jennings \& Brush, 2013).

Push factors are also directly linked to necessity driven motivation due to challenges women face (i.e. less work experience, less education, and more career disruptions) (Kelley et al., 2011). Women motivated by necessity are apathetic to pull factors like being their own boss or controlling their own destiny. Instead, they are stimulated by push factors relating to the need for financial stability and an accommodating work schedule (Jennings \& Brush, 2013). Push factors also encourage women who are opportunity-driven. Hostile work environments (Buttner $\&$ Moore, 1997), frustration with advancement opportunities, or boredom with their previous occupation (Hisrich \& Brush, 1983) motivate these women to transition into entrepreneurship.

Correspondingly, the pull factors that entice women differ from those that persuade men. Male entrepreneurs are heavily influenced by financial and instrumental motives (Jennings \& Brush, 2013), like pull factors relating to improving their social class, increased autonomy, and higher income (Buttner \& Moore, 1997). Their drive arising from pull factors allows them to create and grow a business based exclusively on financial success.

\subsubsection{Success.}

Women see financial success, not as the primary goal, but as one of many reasons to grow a venture (Manolova et al., 2012). Opportunity-driven women entrepreneurs are inspired by pull factors relating to personal satisfaction, including seeking a challenge or the desire for self-realization and self-recognition, instead of money or power (Buttner \& Moore, 1997). This discrepancy is due to the cultural acceptance of male entrepreneurs, allowing them to focus solely on financial gain. In contrast, the natural discrimination of female entrepreneurs forces them to prove themselves through additional measures (Manolova et al., 2012). 
Furthermore, since females have dissimilar motivations for becoming an entrepreneur than males, they view the success of their business differently as well. Women view the decision of becoming an entrepreneur as a life choice, where men view it as a career path (Noble, 1986). Females measure the success of their venture from an intangible view, focusing on professional development, personal growth, self-fulfilment, and social contributions to their families and the community (Buttner \& Moore, 1997). However, traditional measurements of success are based on firm performance, which is in line with the male point of view, focusing primarily on the number of sales, revenue, and job creation (Buttner \& Moore, 1997). Utilizing this type of success measurement is one-sided, causing discrimination against women entrepreneurs (Noble, 1986).

Today, in modern economies, societal changes are slowly promoting the movement of females into traditionally male roles, including entrepreneurship, which is altering the gender stereotypes about agentic characteristics (Kite et al., 2008). High-growth entrepreneurs are considered to be the top performers in the entrepreneurial ecosystem and the key players in promoting economic growth (Stangler, 2010). These entrepreneurs are individuals whose entrepreneurial success can be measured by the rapid growth of the number of sales, employment, or profitability of their firms (Hechavarria, Bullough, Brush, \& Edelman, 2019). Unfortunately, research still shows that high-growth entrepreneurs focusing on commercialization have more male-type characteristics and utilize agentic behaviours. All the while, low-growth entrepreneurs have more women-type attributes and are greater associated with communion (Brush, Carter, Gatewood, Greene, \& Hart, 2004; Heilman, Wallen, Fuchs, \& Tamkins, 2004; Schein, 2001). 
The factors that drive high-growth are associated with an individual's entrepreneurial characteristics, venture strategies and structure, resource availability, and the local environment (Hechavarria et al., 2019). However, due to traditional social roles causing the gendered phenomenon of entrepreneurship, women struggle to become high-growth entrepreneurs. Certain aspects of the entrepreneurial ecosystem have become more difficult to obtain for women, like access to male-dominated markets or funding (Mazzarol, 2014).

Due to social biases, women entrepreneurs are viewed as less desirable by society (Brush et al., 2009; Langowitz \& Minniti, 2007). The variety of discrepancies of motivations, motivational factors, and desired outcomes of entrepreneurial activities between genders gives additional insight as to why women are underrepresented within entrepreneurship. See Appendix A for a table of the differences between male and female entrepreneurs found in prior literature.

Overall, prior literature has found that females differ from males in the motivations that drive their entrepreneurial actions and the way they perceive success. Entrepreneurship is also a male-based phenomenon associated with stereotypically masculine traits, which has created additional barriers for women entrepreneurs (Brush et al., 2018; Jennings \& Brush, 2013). One mechanism for women entrepreneurs to gain support for developing their ventures is through business incubators (BIs).

\subsection{Business Incubators}

\subsubsection{Business incubators in entrepreneurial ecosystems.}

Entrepreneurs and their ventures are a driver for economic activity worldwide because they produce jobs, create wealth, invest in research, innovate, and overall increase productivity (Nicholls-Nixon, Valliere, \& Hassannezhad, 2018; Sandström, Wennberg, Wallin, \& Zherlygina, 2018). Unfortunately, less than half of new ventures will successfully last for five years. Most 
new ventures fail in their first year due to the heightened liability of newness that causes greater threats to their validity (Lasrado, Sivo, Ford, O-Neal, \& Garibay, 2016). For example, new ventures struggle to process new information because they lack organizational design (Cohen, Bingham, \& Hallen, 2018), which causes unclear employee roles and control, and poor managerial structure (Lasrado et al., 2016). New ventures are often also less competitive than established firms. Over time, a business will learn to adopt routines, rules, and standard operating procedures, but during their start-up and growth, they do what they can to survive (Cohen et al., 2018).

Literature has focused primarily on individual entrepreneurs as being the determinant of entrepreneurial success. However, in reality, they are able to thrive only in environments that provide support that can nurture them into established businesses (Ács, Autio, \& Szerb, 2014)). Entrepreneurial ecosystems have developed to promote a culture of entrepreneurs (Ayatse, Kwahar, \& Iyortsuun, 2017) within a specific region and increase the survival rates of new ventures.

The entrepreneurial ecosystem consists of different components that interact to produce support for entrepreneurs (Etzkowitz, 2002). These components can include organizations, such as science parks, business incubators, and R\&D centers, that leverage the resources from the broader ecosystem to provide services that support entrepreneurial activity (Ács et al., 2014; Good, Knockaert, Soppe, \& Wright, 2019). Each ecosystem differs based on the geographical location and community needs, so what works to help new ventures in one location may not work in another (Etzkowitz, 2002).

Although there are many organizations used to support entrepreneurs within an ecosystem, BIs have been found to have the strongest impact on developing successful ventures 
(Harper-Anderson \& Lewis, 2018). The first BI was established in the U.S. in 1959 (Hausberg \& Korreck, 2018), and was followed by exponential growth. There are now over 10,000 BIs worldwide (Bhatli, 2016).

The literature on BIs is fragmented because they were originally researched as a sub-field within other disciplines, like economics (Hausberg \& Korreck, 2018). It has only been in recent years that BIs have been recognized as their own field of study. Additionally, unlike other entrepreneurial support organizations, BIs promote early-stage or developing ventures only (van der Vyver \& van der Vyver, 2017). They are not interchangeable with other terms like science parks or business accelerators, which are used to support more mature ventures (Bergek \& Norman, 2008).

The fragmentation of the BI literature, coupled with the heterogeneity of each BI, has made it difficult to create a universal definition for BIs (Mian, Lamine, \& Fayolle, 2016). For the purposes of this thesis, a BI is broadly defined as an organization that promotes the survival of new ventures through providing tangible (e.g. office space, fabrication materials) and intangible (e.g. coaching, network, programming) support services that will add value to the entrepreneurs through monitoring and assisting in their business start-up and growth (Hackett \& Dilts, 2004).

BIs can also be classified into different typologies based on their primary stakeholders. Some examples include corporate-private incubators, independent commercial, regional, virtual, and university business incubators (Grimaldi \& Grandi, 2005; von Zedtwitz, 2003). University business incubators are particularly distinct because they were originally established to provide professors and students with opportunities to commercialize their research ideas (Klonaridis \& de Klerk, 2017), but have since expanded into multipurpose venues that focus on the promotion of the local community’s needs (Hausberg \& Korreck, 2018). 


\subsubsection{Incubation services.}

The purpose of BIs has not changed over time; they have always focused on promoting entrepreneurial activity. However, how they have fulfilled their purpose has changed since conception. Originally, the focus of BIs was on providing a physical space that was affordable and allowed entrepreneurs to collaborate (Peters, Rice, \& Sundararajan, 2004). Starting in the 1980s, new standalone facilities increased in popularity, separate from a specific company (Mian

et al., 2016), and they began providing additional resources to the entrepreneurs' like networking, coaching, and training (Peters et al., 2004). By the early 2000s, BIs were recognized as being multipurpose innovation centers, where they leveraged the resources from the ecosystem and provided their own to create an incubation process (Galbraith, McAdam, \& Cross, 2019).

With the increased interest in providing different types of support services, prior literature has found that it is essential for all BIs to provide basic services (Cohen et al., 2018), such as physical infrastructure, access to capital, process support, networking, and office support (Breznitz, Clayton, Defazio, \& Isett, 2018). However, the exact mix of the services should depend on the preferences and individual needs of the entrepreneurs (von Zedtwitz, 2003). More specifically, providing entrepreneurial coaching is critical for education and training throughout the entrepreneurial process (Bruneel, Ratinho, Claryssa, \& Groen, 2012, p. 201; Clarysse \& Bruneel, 2007).

\subsubsection{Limitations of business incubators.}

Although there is an abundance of research on BIs, their scope is primarily limited to the services provided to add value, the management, and performance measures (Ayatse et al., 2017; Mian et al., 2016). The studies are also predominantly qualitative, lacking a theoretical 
foundation or consistent use of one theoretical lens (Hausberg \& Korreck, 2018). An overarching theory of the BI process is yet to be developed and unified since the literature is diverse and multidisciplinary (Mian et al., 2016).

Literature has shown that some BIs are not successfully developing entrepreneurial ventures because they have implemented a "one-size-fits-all” model, where all entrepreneurs entering the incubator are treated the same (Kautonen, Pugh, \& Raunio, 2017). The primary reason incubators fail to help entrepreneurs is because they are not providing the right kind of resources, or the resources are not delivered in an effective way (Peters et al., 2004).

However, there is a limited understanding of the interactions between the incubator, entrepreneurs, and the community (Hausberg \& Korreck, 2018). There is also a gap in the understanding of the internal structures of each service within incubators (Ahmad \& Thornberry, 2018). Understanding specific services, like entrepreneurial coaching, is essential to ensure that entrepreneurs are benefitting from incubation.

\subsection{Entrepreneurial Coaching}

Entrepreneurial coaching provides accelerated learning and skill development to encourage venture start-up and growth (Audet \& Couteret, 2012). It can also provide support and direction for building personal competence and external networks (Laukhuf \& Malone, 2015). For the purposes of this thesis, entrepreneurial coaching is defined as "cognitive and managerial process transfer to an individual or to a group in order to satisfy their needs during their entrepreneurial process (Salem \& Lakhal, 2018, p. 89).”

Entrepreneurial coaching is a useful tool to improve venture development through education and training. It is one of the most vital support services provided by BIs because it can increase the entrepreneur's understanding of both managerial and scientific areas of expertise 
(Bruneel et al., 2012). Specifically, coaches can not only provide access to relevant knowledge and expertise for daily organizational decision-making but also help with long-term strategic planning and development (Clarysse \& Bruneel, 2007). Moreover, it is tied to entrepreneurs having greater perseverance and job satisfaction (St. Jean \& Mathieu, 2015).

However, the benefits of entrepreneurial coaching are impacted by the relationship formed between the coach and the entrepreneur, particularly if the coach can communicate effectively (Heydebreck, Klofsten, \& Maier, 2000). Additionally, having a positive coaching relationship can develop a platform where entrepreneurs feel comfortable to discuss their experiences and achievements, while simultaneously gaining recognition and developing the skills necessary for success (St. Jean \& Audet, 2013).

\subsubsection{Developing entrepreneurial self-efficacy.}

The process by which coaching can educate entrepreneurs is through helping them develop entrepreneurial self-efficacy (ESE), which is an individual's confidence in their

capabilities of performing tasks associated with entrepreneurship (Chen, Greene, \& Crick, 1998). ESE plays a critical role in one's motivation and intent to become an entrepreneur, as well as impacting their continued entrepreneurial behaviours and actions (Newman, Obschonka, Schwarz, Cohen, \& Nielsen, 2019). Individual factors such as risk-taking propensity, leadership, passion, and persistence are all impacted by one's level of ESE (Newman et al., 2019), particularly in novice entrepreneurs (Miao, Qian, \& Ma, 2017).

Improving ESE has become the most critical target of entrepreneurial education and training programs because it will increase the number of people willing to become entrepreneurs and maintain their persistence after venture creation (Newman et al., 2019). Educators and public 
policymakers have had an increasing interest in the effect of ESE because it is a driving factor for expanding the entrepreneurial ecosystem.

However, prior research has found that, on average, female entrepreneurs have lower ESE than males (Newman et al., 2019; Zhao, Seibert, \& Hills, 2005). Although some academics believe that women only have lower ESE in certain entrepreneurial activities depending on the way it is measured (Coleman \& Kariv, 2013; Mueller \& Dato-On, 2008), ESE remains as a driving factor for behaviour.

\subsection{1a Pathways for developing ESE.}

Research has found four pathways in which ESE can be developed and altered within an individual: mastery experience, vicarious learning, social persuasion, and judgement of one's physiological state (Bandura, 1977). Mastery experiences are the most influential in developing ESE because the experiences are structured to gain skills used for coping and controlling potential threats that alter an individual's personality. Subsequently, ESE is impacted by vicarious learning through which an individual observes someone similar to themselves having success, causing a change in the individual's beliefs that they too could succeed. Thirdly, social persuasion is when one is verbally persuaded into believing they are capable of success, reducing self-doubt. However, research shows that social persuasion cannot sustain high levels of ESE alone, and must be accompanied by the other sources. Lastly, ESE is impacted by the individual's interpretation of their own physical and mental states that affect their capabilities, such as stress or fatigue (Bandura, 1994).

\subsubsection{Using ESE for successful coaching.}

Four key factors to having a successful coaching relationship have been identified, including having homophily, building trust, role modelling, and using the right coaching style. 
Homophily, or the tendency for people to have ties with others similar to them, plays a role in the ability for entrepreneurs to learn vicariously. If they do not view their coach as being similar to themselves, then they cannot envision gaining the same level of success (Yang, Kher, \& Newbert, 2019). Similarly, vicarious learning is impacted by the level of trust and closeness because, without it, the conversations may not be as open or honest (Laukhuf \& Malone, 2015; Mansoori, Karlsson, \& Lundqvist, 2019; Yang et al., 2019). By viewing the coach as a professional role model, it can improve social persuasion and vicarious learning through aspiring to be like them (Bandura, 1994; Laviolette, Lefebvre, \& Brunel, 2012). Lastly, the coaching style, or the type of instruction used for each session, impacts the effectiveness of the experience for the entrepreneur. If the coach uses an effective style, the entrepreneur can gain mastery experiences and independence (St. Jean \& Audet, 2013).

\subsubsection{Coaching women entrepreneurs.}

Female entrepreneurs have been found to benefit more greatly from entrepreneurial coaching than males. One reason is that women tend to be more relationship-focused, having stronger communal and relational skills. These skills cause them to be more attentive to details, allowing for a deeper understanding of their weaknesses while also being open to change (BarNir, Watson, \& Hutchins, 2011).

Females also benefit from coaching due to the negative gender stereotypes that create barriers for them being entrepreneurs. Particularly in male-dominated industries, female entrepreneurs feel they must have mastery experiences to develop ESE because of the negative societal pressure of not conforming to the traditional industries. In contrast, in female-dominated industries, women entrepreneurs feel they can develop ESE the most through social persuasion since they fall within what is widely accepted by society (Sweida \& Woods, 2015). 
Unfortunately, not all coaching programs used to improve ESE and venture development are sufficient, specifically when assessed from a gendered perspective. Gender stereotypes coming from the coach can also impair their coaching relationship. For example, females in male-dominated industries are often viewed as less credible than males (Laukhuf \& Malone, 2015; Yang et al., 2019). Therefore, a coach may undervalue females and coach them differently than they would a male entrepreneur.

These stereotypes also play a role in the portrayal of entrepreneurs in society.

Professional entrepreneurial role models in media and broader communities are typically males, which attract other male entrepreneurs. Consequently, female entrepreneurs lack professional role models who can help inspire them to lead them through their entrepreneurial experience. Most female entrepreneurs resort to gaining coaching through personal role models, such as family or friends, who may not be able to provide feedback based on expertise (BarNir et al., 2011). Having a professional role model for female entrepreneurs is imperative for gaining ESE, particularly having same-gender role models in male-dominated industries to improve their ESE through social persuasion and vicarious learning.

\subsection{Summary}

Although the field of women's entrepreneurship has significantly expanded in the past 30 years, there is still a lack of in-depth qualitative work being used to build a strong theoretical framework. This is partially due to the added barriers that women, in particular, must overcome that may deter them from creating their own businesses (Jennings \& Brush, 2013), such as their motivation for becoming an entrepreneur, lower levels of entrepreneurial self-efficacy, and the impact of public policies. 
Entrepreneurial coaching in BIs is a critical service for education and training for women entrepreneurs to help them develop successful ventures. Since females are both stereotyped against and provided with less external support, coaching can provide them with more benefits than males when effective practices are put into place.

With the dynamic disparities between male and female entrepreneurs, it stands to reason that entrepreneurial coaching will impact both genders differently. Therefore, it is critical to assess if the coaching services are benefitting both female and male entrepreneurs equally. This study aims to establish patterns of the coaching experience within BIs from a gendered perspective to fill this gap within the literature. This study intends to provide empirical evidence for how entrepreneurial coaching is understood by both male and female entrepreneurs, with the potential to make a contribution to the three streams of literature and provide insight on how to improve the current coaching services within BIs. 


\section{Chapter 3: Methodology}

This inductive, theory-building study examined how business incubation services, particularly entrepreneurial coaching, influence entrepreneurial outcomes from a gendered perspective. Specifically, the perception of male and female entrepreneurs and entrepreneurial coaches were explored to understand how coaching enables (or constrains) personal and venture development. This study received ethics approval from the Research Ethics Board at Ryerson University, protocol number 2019-372, as of November 13, 2019.

Inductive studies place emphasis on the real-world context where a phenomenon occurs (Eisenhardt \& Graebner, 2007) and is particularly helpful for the progression of "grand challenges." Meaning, situations where there is a lack of understanding or theory around the occurrence (Eisenhardt, Graebner, \& Sonenshein, 2016). An inductive approach is appropriate for this study because entrepreneurial coaching is a complex phenomenon, and taking a gendered perspective with this particular focus is novel. Additionally, inductive methodologies are widely deemed suitable when answering research questions asking "how" or "why" (Eisenhardt et al., 2016; Yin, 2003) such as the proposed research question.

\subsection{Selection of Participants}

\subsubsection{Sampling strategy.}

This study relied on purposive sampling, where entrepreneurs participating in business incubators at Ryerson University were selected based on their ability to illustrate and expand the understanding of the constructs or processes of the focal phenomenon 'entrepreneurial coaching' (Denzin \& Lincoln, 2018; Glaser \& Strauss, 1967). Although purposive sampling reduces the generalizability of the findings, it provides greater opportunity for developing a deeper understanding of entrepreneurial coaching. It allows for gender comparisons by excluding 
extraneous variables. In qualitative studies, purposive sampling is the most common form of non-probabilistic sampling (Guest, Bunce, \& Johnson, 2006). Prior literature shows that theoretical saturation, where no new data is observed by increasing the number of participants (Boychuk Duchscher \& Morgan, 2004), for qualitative interviews typically occurs between six to twelve participants (Guest et al., 2006). Therefore, it was expected that a minimum of six interviews with entrepreneurs would be conducted or until theoretical saturation was reached (Boychuk Duchscher \& Morgan, 2004; Guest et al., 2006).

\subsubsection{Inclusion criteria.}

Additional extraneous factors were reduced by ensuring that participants were selected based on strict inclusion criteria. The inclusion criteria found in Table 2 were implemented because it was imperative for the participants to be as similar to one another as possible, with the main difference being gender. Additionally, the timeframe was important because retrospective data was collected, where the participants must recall their experiences and provide specific examples (Eisenhardt \& Graebner, 2007).

Table 2: Inclusion Criteria

\begin{tabular}{|c|c|}
\hline Criteria & Rationale \\
\hline $\begin{array}{l}\text { 1. Their venture must be at an } \\
\text { early (validation) stage. }\end{array}$ & $\begin{array}{l}\text { Allows the business to be at a stage where coaching is } \\
\text { imperative to help the venture develop and grow. }\end{array}$ \\
\hline $\begin{array}{l}\text { 2. Must have limited experience } \\
\text { working as a start-up founder } \\
\text { (have started two or fewer } \\
\text { businesses). }\end{array}$ & $\begin{array}{l}\text { Allows the entrepreneur to be at a stage where } \\
\text { coaching is imperative to help them develop their } \\
\text { entrepreneurial skills. }\end{array}$ \\
\hline $\begin{array}{l}\text { 3. Must be currently incubating } \\
\text { for at least two months or } \\
\text { have graduated from the } \\
\text { incubator within the past } \\
\text { year. }\end{array}$ & $\begin{array}{l}\text { Interviewing participants too early (less than two } \\
\text { months) may mean they have not had many affiliations } \\
\text { with a coach or realized any benefits/constrains. } \\
\text { Interviewing participants too late (over a year past } \\
\text { graduation) may cause participants to have forgotten } \\
\text { certain aspects of their coaching experience or } \\
\text { misremember scenarios. }\end{array}$ \\
\hline $\begin{array}{l}\text { 4. Must be a Canadian citizen or } \\
\text { permanent resident. }\end{array}$ & $\begin{array}{l}\text { This reduced extraneous factors related to being a } \\
\text { newcomer in Canada. }\end{array}$ \\
\hline
\end{tabular}




\subsection{Recruitment Process}

Initially, the plan was to recruit entrepreneurs through the coaches that they work with, so the recruitment process took place through three main avenues; referral to coaches through the incubator director and personal contacts, direct contact to coaches, and use of posters to attract entrepreneurs. See Figure 1 for a flowchart of the recruitment process.

Information about the study was emailed to the directors of four chosen incubators within Ryerson University. This email included an explanation of the nature of the study, the consent letter for participation, contact information, a script to invite coaches, and a poster to recruit entrepreneurs. A follow-up email was sent to the incubator directors if there was no response provided after five business days. Once the incubator director approved, posters were distributed as they saw fit to raise awareness of the study and encourage current incubation tenants (the entrepreneurs) to participate. Email invitations with the study information were also forwarded to coaches. This process was replicated for the primary researcher's personal contacts within the incubators.

If no response was received from the coaches (either accepting or rejecting) after sending the first email, a follow-up email was sent by either the incubator director or personal contact. If a coach or entrepreneur agreed to participate in the study, they directly contacted the primary researcher. After communication was initiated, the potential participants were screened for the inclusion criteria, and if they were eligible, then an interview was scheduled and conducted. After conducting the interview, all participants received an email thanking them for their time. Additionally, to create a snowball effect, any coaches who were interviewed were asked to forward the study information via email to entrepreneurs within their incubator. If the 
entrepreneurs agreed to participate, they contacted the primary researcher, and the cycle of screening, scheduling, and conducting an interview was repeated.

Direct contact was also made with coaches whose contact information was publicly available. Most incubator websites provide information about their currently employed coaches. These coaches also have social media accounts and company websites that provide publicly available information where their contact information was obtained. LinkedIn was also used to find contact information for coaches by using key search terms, such as the incubator name, to identify people who have mentioned this organization within their profiles. After their contact information was collected, the primary researcher sent the potential candidates' information about the study via email and asked if they would like to participate. The process would then continue as previously mentioned.

Figure 1: Flowchart of Recruitment Protocol

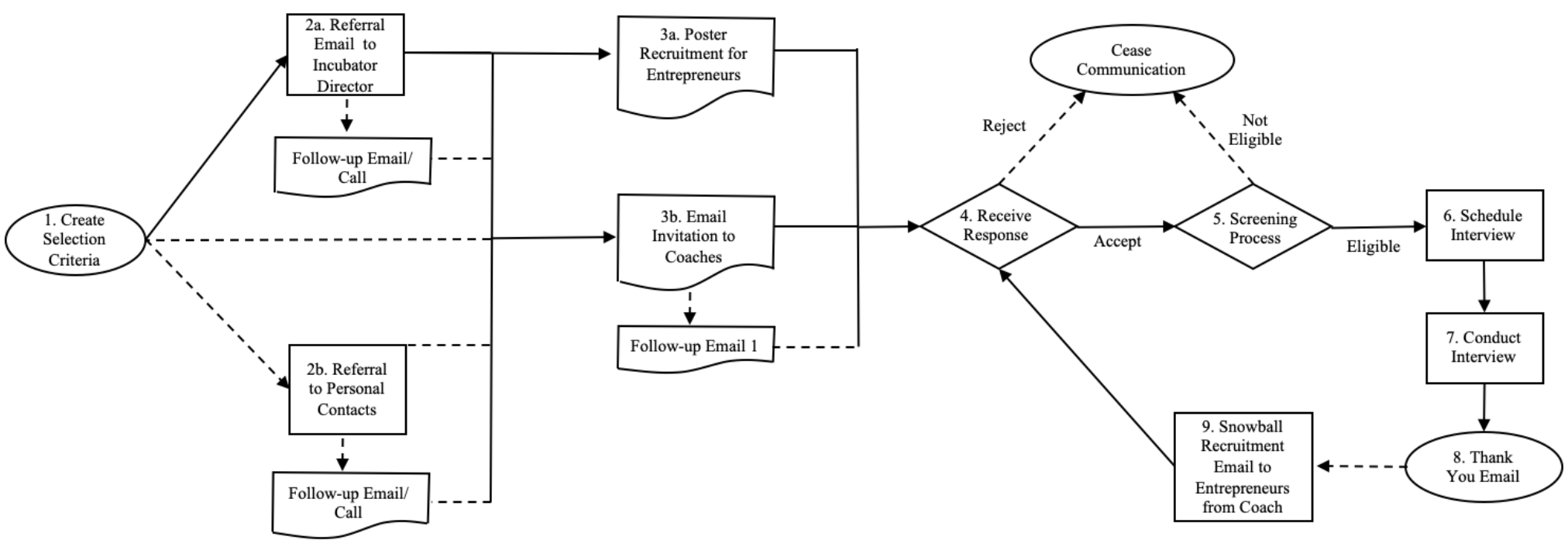

Fifteen entrepreneurs were recruited for the study. Three of these participants were obtained through snowball recruitment from coaches, while twelve were recruited via posters. Eleven were eligible to participate overall. 


\subsubsection{Obtaining informed consent.}

Before any interviews were conducted, participants were required to sign a consent letter either electronically or on paper. Regardless of which format the participant used to sign, the contents of the consent letter were reiterated to the participant before conducting the interview. Time was allowed for any questions or concerns to be addressed. The consent letter was distributed through several avenues, including a digital link in all invitation emails, a QR code on the posters, and a paper copy provided in person before proceeding with the interview.

\subsubsection{Recruitment challenges.}

Although this study had a clear plan in place for recruitment, there were still unforeseen challenges, specifically related to gaining access to participants. See Figure 2 for the data collection and analysis timeline. Once ethics approval was received in mid-November, the first incubator director was contacted. Unfortunately, the response time was slower than expected, and communication was later deferred to the director's assistant. By the time approval was received to forward the study information, the holiday season was fast approaching, and there were no responses received from potential participants before the end of 2019.

As 2020 began, communication with the second incubator director was made, and approval to share the study was received quickly. Simultaneously, communication with the first incubation director was re-established, and follow-up emails were sent to coaches. At this point, the study information was also sent to a personal contact of the primary researcher within the first incubator. They approved and forwarded the study information as well. By mid-January, still, no participants had volunteered.

Entering into the second half of January, the third and fourth incubator directors were contacted, approval was received, and the study information was shared. As the end of January 
approached, as a last resort, coaches were emailed directly about the study. This proved to be the most successful method because, within the week, seven coaches had agreed to participate. Additionally, at this time, the five entrepreneurs responding to the posters within their incubator agreed to participate as well. After screening all interested participants, interviews for four coaches and five entrepreneurs were scheduled leading into February.

At the beginning of February, ten more entrepreneurs responded, were screened, and the six that were eligible had interviews scheduled by mid-February. Three more coaches also responded with interest but were not eligible to participate. The final interview was conducted in the last week of February.

It was also a challenge to get participants to meet in person. Therefore, some interviews were conducted via phone call, which only allowed for verbal communication, and restricted the connection made between the participant and researcher through visual cues, such as body language. Also, some participants' interviews had to be shortened because they arrived late or had other obligations to attend afterwards. These issues were not controllable but potentially limited the data collected.

Figure 2: Data Collection and Analysis Timeline

\begin{tabular}{|c|c|c|c|c|c|}
\hline & Nov-19 & Dec-19 & \multicolumn{2}{|c|}{ Jan-20 } & Feb-20 \\
\hline Ethics Approval & & & & & \\
\hline Participant Recruitment & & & & & \\
\hline Participant Screening & & & & & \\
\hline Scheduling Interviews & & & & & \\
\hline Conducting Interviews & & & & & \\
\hline Transcribing Interviews & & & & & \\
\hline Data Analysis & & & & & \\
\hline
\end{tabular}




\subsection{Data Collection}

\subsubsection{Sample description.}

The final sample for this study included eleven entrepreneurs (five males and six

females). For comparative purposes, information on attributes of the individual respondents were identified, such as their academic background, professional work experience, prior entrepreneurial work experience, venture type, and external incubation experience. See Table 3 for a description of the participants' backgrounds. This information was collected via interview responses and publicly available resources, such as LinkedIn, where the participants share their personal information. All of this was recorded to identify factors that could influence their perceived benefits from coaching.

Table 3: Description of the Entrepreneurs' Background

\begin{tabular}{|c|c|c|}
\hline & Female n=6 & Male n=5 \\
\hline Education & 6 Bachelor's degree or higher & 2 Bachelor's degree or higher \\
\hline $\begin{array}{c}\text { Non-Entrepreneurial } \\
\text { Work Experience }\end{array}$ & $\begin{array}{c}2<\text { five years, 1 five-ten years, } \\
3>\text { ten years }\end{array}$ & 2 five-ten years, 3 $>$ ten years \\
\hline $\begin{array}{c}\text { Entrepreneurial } \\
\text { Experience }\end{array}$ & $\begin{array}{c}\text { 1 previous start-up experience, } \\
5 \text { no start-up experience }\end{array}$ & $\begin{array}{c}\text { 1 previous start-up } \\
\text { experience, } 4 \text { no start-up } \\
\text { experience }\end{array}$ \\
\hline Venture Type & 5 social, 1 other & 1 social, 4 other \\
\hline Incubation Experience & $\begin{array}{c}4 \text { currently co-incubating, } 2 \\
\text { prior external experience }\end{array}$ & $\begin{array}{c}\text { 2 currently co-incubating, 3 } \\
\text { no prior external experience }\end{array}$ \\
\hline
\end{tabular}

The selection sample was recruited from four business incubators at Ryerson University. However, the participants also shared their coaching experiences at eight external incubators located throughout the Greater Toronto Area.

\subsubsection{Semi-structured interviews.}

Data collection was performed by conducting semi-structured interviews that follow a pre-determined interview guide. The guide included questions that related each entrepreneur's 
coaching experience during business incubation; for example, "What has been the most important or valuable thing you gained from coaching?" See Appendix B for the full interview guide. Semi-structured interviews are the ideal approach for this study because the interviews can be targeted for the focal phenomenon and positioned to provide deeper insights (Yin, 2003).

All questions were open-ended, which created a more conversational interview where the participants could choose to focus on the factors they deem as most important to their experience of entrepreneurial coaching during incubation. These questions also provided the interviewer with the ability to redirect the conversation when off-topic or circle back to something significant (Denzin \& Lincoln, 2018). Probing questions were used in addition to the interview guide to ask for illustrative examples of specific aspects of their coaching experience.

\subsection{Dependability}

For a qualitative study to be 'dependable,' there needs to be consistency within the methodology that allows for replicability of the study with similar participants within a similar context (Guba, 1981). Therefore, this study has addressed dependability by clearly outlining the data collection and analysis procedure used. Specifically, a 'decision-trail' (Noble \& Smith, 2015) of the thematic coding process was documented (see section 4.1) to understand the types of concepts that arose from the raw data and the process of interpretation into dimensions of coaching.

\subsection{Credibility}

'Credibility' is about collecting data that represents the true focal phenomenon, entrepreneurial coaching (Guba, 1981). The methodology must account for both research and personal biases that could influence the participant's responses or interpretation of the responses (Noble \& Smith, 2015; Sandelowski, 1993). Interviews as a source of data collection can be 
untrustworthy because of factors such as poorly constructed questions, recall bias, response bias, and reflexivity (Yin, 2003). Precautions were taken to reduce the impact of these challenges.

Recall bias is when a participant does not accurately recount an experience from the past (Huber, 1985; Yin, 2003). This study relies primarily on retrospective data, where the participants must recall their experiences and provide specific examples (Eisenhardt \& Graebner, 2007). Therefore, accurately remembering their experiences is essential.

To reduce recall bias, and any confounding explanations for the results, a strict timeframe was set in the inclusion criteria only to allow participants who have current or recent coaching experience. By selecting knowledgeable and relevant participants who are currently incubating, recently graduated, or working within the incubators, the insights provided can be richer and more useful (Denzin \& Lincoln, 1994; Eisenhardt \& Graebner, 2007). Also, the interview guide asked questions in chronological order, beginning with the participants coaching expectations, process, and overall experience. Chronologically remembering events helps reduce recall bias (Huber, 1985) and allows for easier across-gender comparisons among participants.

Response bias is when the participant is not honest in their responses to the interview questions (Eisenhardt \& Graebner, 2007). This was reduced by reiterating the ethical practices of the study, such as confidentiality and voluntary nature, not only in the consent letter but also verbally before conducting the interview.

Reflexivity is when the participant tells the interviewer what they think they want to hear (Yin, 2003). For this study, reflexivity was reduced by asking open-ended questions that let the participant choose what they wanted to discuss while allowing for the interviewer to remain impartial (Creswell, 1998). Also, reflexivity was reduced during the analysis process by using 
'conceptual memoing' where the higher-level themes and ideas from the data were extracted (see section 4.1) before developing dimensions based on individual quotes (Holton, 2010).

Personal biases were addressed by reflecting on the data and removing any responses that were prompted from leading or loaded probing questions. Audio recording each interview allowed for the raw data to be repeated to check for accuracy and remain true to the participants word. Although this study is taking a gendered approach, the interview questions did not address gender differences unless the participant alluded to it first. The findings were also reviewed by the primary researcher's thesis supervisor to ensure that personal biases were not impacting the findings. Additionally, a strict study protocol was followed for each participant that reduced the effect of personal bias, such as treating one group of participants differently than another.

\subsection{Transferability}

'Transferability' refers to the level at which the study analysis can be used in other contexts (Guba, 1981; Maxwell, 1992). When using purposive sampling, transferability is limited because the participants were chosen for fulfilling specific criteria that were relevant to the study (Denzin \& Lincoln, 1994; Guest et al., 2006). However, through data triangulation between different sources of participants, both entrepreneurs and coaches, a more comprehensive overview of entrepreneurial coaching was obtained (Patton, 1999). See Appendix C for the supplementary analysis of coaches included in the study. Through using multiple, diverse outlooks on entrepreneurial coaching, the insights of the entrepreneurs were confirmed by the coaches, therefore allowing for the study to be more generalizable (Maxwell, 1992; Yin, 2003). 


\section{Chapter 4: Data Analysis}

\subsection{Analysis Procedure}

\subsubsection{First-order coding.}

Each interview was audio-recorded and manually transcribed. The final sample of participants chosen to be included in the data analysis were six female entrepreneurs and five male entrepreneurs. For these eleven participants, almost eight hours of commentary was recorded, with an average interview length of approximately 42 minutes and each transcription averaging to eleven single-spaced pages.

The initial coding process was done by hand. All 11 interviews were printed and read through once to comprehend the type of responses that were provided by the whole sample. All of the interviews were then read again while performing conceptual memoing, or making margin notes of themes (Holton, 2010) that corresponded to the interview questions. This is consistent with inductive research practices (Eisenhardt et al., 2016). Since the interviews were semistructured, the responses and probing questions varied depending on the participant.

After reading the interviews a second time, all margin notes were assessed by iterating between each interview and the interview guide. This process revealed the first-order codes that were associated with the perceived value of what the coach provided; whether it benefitted their personal and/or venture development (benefit), whether it was provided but either did not add value or hindered their personal and/or venture development (needs improvement), or whether it was not offered but was expected (missing). See Figure 3 for the criteria for the first-order codes. 
Figure 3: First-Order Codes

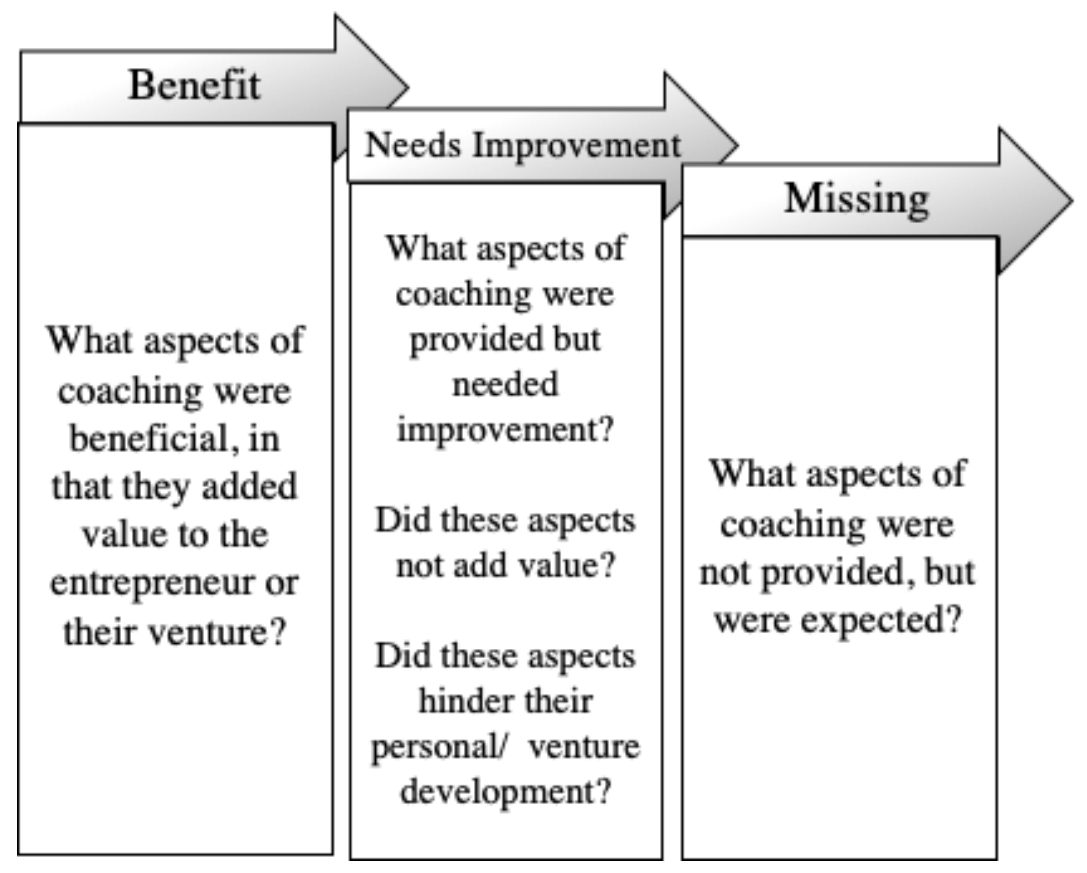

The analysis process then transitioned from paper to NVIVO, a qualitative data analysis software that is used by researchers to help maintain large volumes of data and organize it into thematic patterns. Using NVIVO, all 11 interviews were coded individually with the first-order codes.

It should be noted that no distinction was made between internal coaching, meaning the staff of the incubator and external coaching, referring to temporary coaches hired from outside of the incubator. This was because both internal and external coaches were deemed to be providing entrepreneurial coaching.

\subsubsection{Second-order coding.}

For the next phase of analysis, the respondents were then divided into two groups based on the participant's gender. This division was necessary to allow for within-gender comparisons (i.e. only females or only males) and across-gender comparisons (i.e. male vs. female). Using both types of group comparisons creates a deeper understanding of the entrepreneurs' coaching 
experience (Eisenhardt, Graebner, \& Sonenshein, 2016) and increases the generalizability of the findings (Eisenhardt, 1989).

After the division of participants, analysis proceeded with second-order coding by establishing concepts associated with each of the first-order codes (benefit, needs improvement, missing). A similar process to the Gioia methodology for concept development was used to identify the second-order codes (Gioia, Corley, \& Hamilton, 2013). This began by reading the sections that had been first-order coded on NVIVO for the female participants and line-by-line open coding the data (Gioia et al., 2013). Margin notes of any and all concepts that were easily identifiable were made. To identify these concepts, questions similar to Glaser's 1998 grounded theory approach were kept in mind, such as, "What is this data a study of? What category does this incident indicate? What is actually happening in the data? What is the main concern being faced by participants?" (Glaser, 1998, p. 140; Holton, 2010). For the female participants, fortythree concepts were identified. Then, the process was repeated for the male participants. The same concepts were used where applicable and new concepts were added when necessary. Through this process, the most significant information was identified, and a total of fifty-two concepts emerged from both genders.

Next, the fifty-two concepts were organized into categories of similar concepts. This process began by first performing within-gender comparisons, then proceeded with acrossgender comparisons to create seven categories of second-order concepts. See Figure 4 for the categorization of the second-order concepts.

The seven concept categories were then condensed into seven sub-dimensions (business expertise, perspective, referral, compatibility, shared experience, empathy, and female-specific needs). These sub-dimensions were defined based on the overall meaning of each concept 
category (Gioia et al., 2013). This occurred through iterating between the data where the fiftytwo concepts were identified and prior literature on entrepreneurial coaching and women's entrepreneurship. This process was important for understanding how the emerging themes related to prior literature and if any new themes were uncovered through the data (Gioia et al., 2013). See Figure 4 for the sub-dimensions that emerged from the second-order concepts.

Lastly, the seven sub-dimensions were distilled into three dimensions of coaching that impact entrepreneurial outcomes. This occurred by identifying how the sub-dimensions related to each another based on the area of entrepreneurship that they impact. Through this process, three dimensions of coaching were identified and defined; (1) venture support- providing guidance and knowledge about venture start-up and growth, which incorporates three sub-dimensions (business expertise, perspective, and referral); (2) emotional support- demonstrating a deeper understanding and genuine concern for the entrepreneur by providing reassurance and building a personal relationship, which includes three sub-dimensions (compatibility, shared experience, and empathy); (3) gender sensitivity- the acknowledgment of gender-based differences between male and female entrepreneurs and proving coaching services accordingly. See Figure 4 for the dimensions that emerged from the sub-dimensions and a visual of the second-order coding process. 
Figure 4: Visual Representation of Second-Order Coding Process
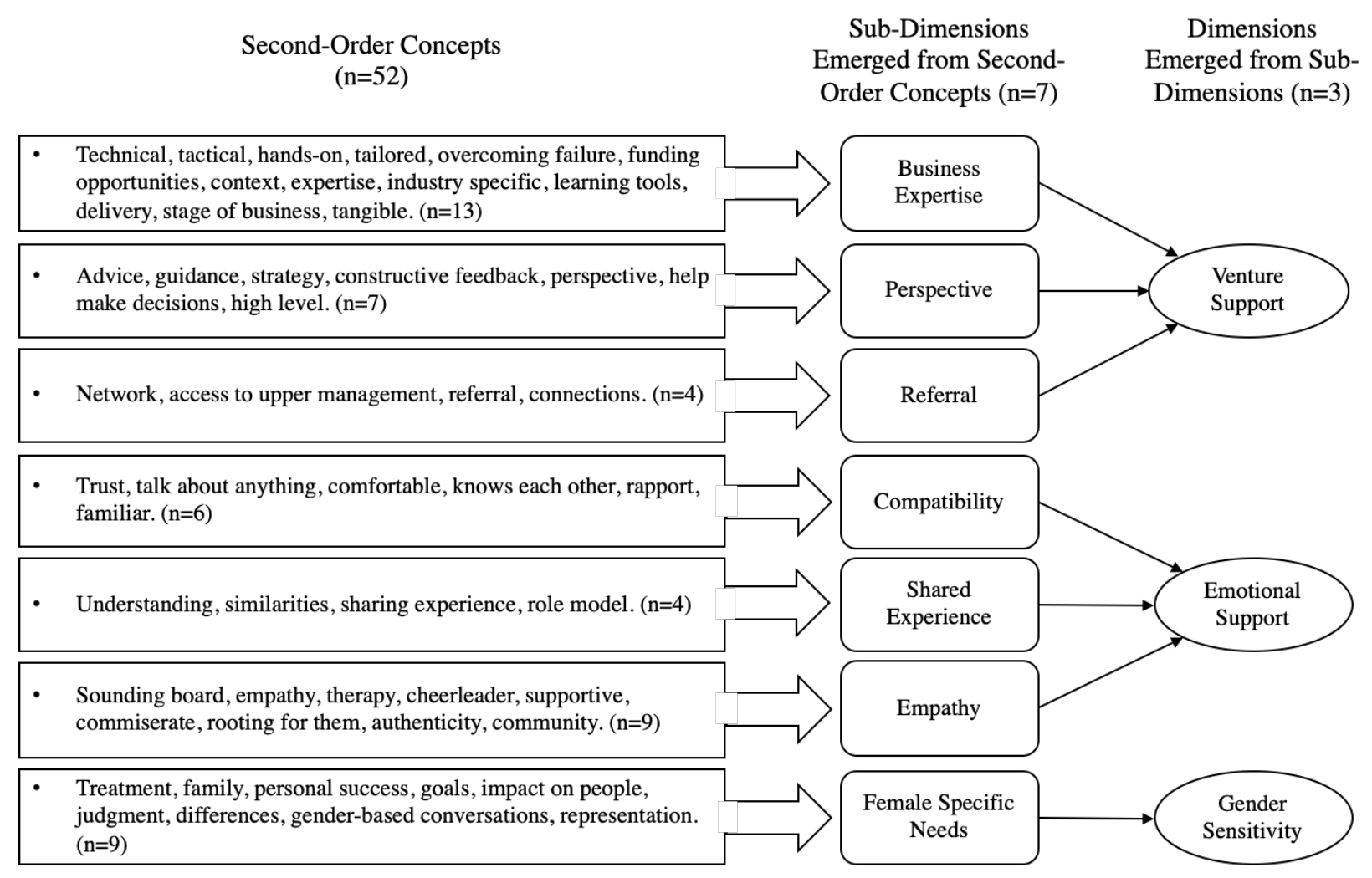

Additionally, the second-order coding process also revealed personal investment as a factor that affects the relationships between the coaching dimensions and the entrepreneurial outcomes. Personal investment refers to the level of commitment and interest the coach puts into the entrepreneur.

Up until this point of the coding process, the second-order codes remained in the margin notes. Therefore, the final step included coding each interview with the emerged dimensions and sub-dimensions in NVIVO, starting with the females and then with the males. See Table 4 for the definitions of each dimension. 
Table 4: Coaching Dimension Definitions

\begin{tabular}{|c|c|c|c|}
\hline Dimension & Definitions & $\begin{array}{c}\text { Sub- } \\
\text { Dimension }\end{array}$ & Definition \\
\hline \multirow{3}{*}{ Venture Support } & \multirow{3}{*}{$\begin{array}{c}\text { Providing guidance and } \\
\text { knowledge about venture start- } \\
\text { up and growth }\end{array}$} & $\begin{array}{l}\text { Business } \\
\text { Expertise }\end{array}$ & $\begin{array}{c}\text { Task oriented knowledge, specific to } \\
\text { one area of the business or one } \\
\text { industry }\end{array}$ \\
\hline & & Perspective & $\begin{array}{l}\text { High-level guidance of the business } \\
\text { strategy }\end{array}$ \\
\hline & & Referrals & $\begin{array}{l}\text { Connection to someone or something } \\
\text { else that may be able to add value }\end{array}$ \\
\hline \multirow{3}{*}{$\begin{array}{l}\text { Emotional } \\
\text { Support }\end{array}$} & \multirow{3}{*}{$\begin{array}{c}\text { Demonstrating a deeper } \\
\text { understanding and genuine } \\
\text { concern for the entrepreneur by } \\
\text { providing reassurance and } \\
\text { building a personal relationship }\end{array}$} & Compatibility & $\begin{array}{l}\text { Interpersonal relationship where } \\
\text { familiarity and trust are established }\end{array}$ \\
\hline & & $\begin{array}{c}\text { Shared } \\
\text { Experience }\end{array}$ & $\begin{array}{l}\text { The coach shares their personal } \\
\text { experience with a similar problem }\end{array}$ \\
\hline & & Empathy & Commiseration and encouragement \\
\hline $\begin{array}{l}\text { Gender } \\
\text { Sensitivity }\end{array}$ & $\begin{array}{l}\text { Acknowledgment of gender- } \\
\text { based differences between } \\
\text { male and female entrepreneurs } \\
\text { and providing coaching services } \\
\text { accordingly }\end{array}$ & & \\
\hline
\end{tabular}

\subsubsection{Grounded theory development.}

Following a grounded theory approach, where a theory rises directly from observing patterns in the data (Boychuk Duchscher \& Morgan, 2004), tables were made using Excel to condense and organize representative quotes from the interviews into the three corresponding coaching dimensions; venture support, emotional support, and gender sensitivity. Beginning with the female entrepreneurs, all coded data was entered into columns broken down by dimension and sub-dimension. This process was repeated for male entrepreneurs in a separate table. All quotes were cross-checked with the definitions of each dimension to confirm that they were representative of the category. Then a final table with the total participant count per dimension was created. Analysis proceeded by conducting within-gender and across-gender comparisons were performed to understand similarities and differences between male and female entrepreneurs for each dimension. These final comparisons resulted in the findings below. 


\subsection{Analysis Findings}

All eleven participants perceive coaching as being beneficial in aiding in their personal and/or venture development. However, eight of the participants also believed that there were aspects of coaching that needed to be improved, and all eleven participants commented on aspects that were missing entirely. Although the participants broadly agreed on the dimensions (second-order codes) of coaching within each value category (first-order codes), gender-based differences were observed.

Additionally, one factor that impacted the relationship between the dimensions of coaching and the entrepreneurial outcomes was identified. Six entrepreneurs believed this factor was beneficial when provided, and five entrepreneurs expressed that it needed improvement. This factor is independent of gender, meaning it impacts both male and female entrepreneurs equally.

See Table 5 for a summary of the responses categorized by gender; these responses are based on the number of individual participants, not on how many responses each participant had for each dimension. In the subsequent paragraphs, the four dimensions of coaching will be explained in detail, along with the similarities and differences observed in within and across-gender group comparisons. 
Table 5: Total Participant Counts per Dimension

\begin{tabular}{|c|c|c|c|}
\hline Value & Dimension & Female ( $\mathbf{n}=\mathbf{6})$ & Male (n=5) \\
\hline \multirow{4}{*}{ Benefit } & Venture Support & 6 & 5 \\
\cline { 2 - 4 } & Emotional Support & 4 & 4 \\
\cline { 2 - 4 } & Gender Sensitivity & 0 & N/A \\
\cline { 2 - 4 } & Personal Investment & 3 & 3 \\
\hline \multirow{4}{*}{$\begin{array}{c}|c| \\
\text { Improveds }\end{array}$} & Venture Support & 4 & 4 \\
\cline { 2 - 4 } & Emotional Support & 1 & 1 \\
\cline { 2 - 5 } & Gender Sensitivity & 5 & N/A \\
\cline { 2 - 5 } & Personal Investment & 3 & 2 \\
\hline \multirow{4}{*}{ Missing } & Venture Support & 4 & 4 \\
\hline & Emotional Support & 5 & 0 \\
\cline { 2 - 4 } & Gender Sensitivity & 6 & N/A \\
\cline { 2 - 5 } & Personal Investment & 1 & 0 \\
\hline
\end{tabular}

\subsubsection{Venture support.}

'Venture support' in the context of this thesis refers to the guidance and knowledge the coach provides about venture start-up and growth. This includes three sub-dimensions: (1) business expertise- task-oriented knowledge, specific to one area of the business or one industry; (2) perspective- high-level guidance of the business strategy; and (3) referrals- connection to someone or something else that may be able to add value. Overall, venture support is perceived as being equally important for both male and female entrepreneurs. See Table 6 for the total number of participants who commented on venture support.

Table 6: Venture Support Participant Count

\begin{tabular}{|c|c|c|c|c|c|c|}
\hline \multicolumn{9}{|c|}{ Venture Support } \\
\hline & Business Expertise & \multicolumn{2}{c|}{ Referral } & \multicolumn{2}{c|}{ Perspective } \\
\hline & Female & Male & Female & Male & Female & Male \\
\hline Benefit & 6 & 5 & 3 & 4 & 4 & 4 \\
\hline Needs Improvement & 4 & 4 & 0 & 1 & 0 & 1 \\
\hline Missing & 3 & 1 & 1 & 3 & 1 & 1 \\
\hline
\end{tabular}




\subsection{1 a Perceived as benefit.}

Venture support was identified by all eleven male and female participants as being highly

beneficial and view each sub-dimension as a value add.

Each of the eleven participants specifically referenced their coach's task-oriented knowledge, or

\section{business expertise:}

"I reached out to the [coach] that has experience doing that, gave him a brief overview of my company, and I said, 'this is my issue, and this is what we're doing.' Then he came out saying, 'Here are the things you should do.' Then we went back and forth, asking questions, getting clarification until I was like 'okay, got it. This is exactly what I was looking for.' That was an amazing meeting. I came in with a question and left with a solution." - Respondent 1020301

"I spoke with [my coach], and I told him that I was ready to get the boxes made up so that we can start shipping the product, and he told me not to worry about that. He said, 'You have a product, and it works, and you've done a year of testing. You need to get out there and start opening doors for people just to even look at it.' He put my energy in the right direction, and that's great advice because you have to sell it." - Respondent 26020901

"There was a lot of pitch coaching every single day, which made it an invaluable skill.I can see now that I'm very comfortable pitching any product because of that. It was very helpful in that sense." - Respondent 1020902

"I was very new to social entrepreneurship, and [my coach] helped me understand how to build out a logic model, how to measure impact, and what it was we were trying to do." - Respondent 2702090201

Seven participants (four male and three female) commented on their coach providing referrals to other useful resources:

"[My coach] basically said, 'Who in my Rolodex can I connect you to?' and that was helpful." - Respondent 4020901

"Some of the [coaches] try to create connections for you, which are always helpful. One [coach] provided connections to a brand for us to speak with to get them on our platform, which is a pretty big deal for us." - Respondent 3020901 
"I attended a launch event, and [my coach] ended up introducing me to so many people. He stayed with me for almost half an hour and introduced me to all of those people and asked me to pitch my social enterprise, which I thought was so cool. He did not have to hang out with me, but he did, and I think that was really great." - Respondent 26020902

"My coach had connected me with some people who might be interested in buying my products who were in his group. And then also spreading the word around and saying like, 'She's having a pop up here, go check it out.' So, kind of helping to get those sales." - Respondent 2020902

Another eight participants (four male and four female) commented on their coach's ability to provide high-level guidance or perspective:

"There tends to be kind of that one-liner that just sits with you after you have a [coaching] session. Sometimes there is something that is so blatantly obvious that you just forgot, or you haven't talked about until you have a fresh set of eyes talk to you about it. And sometimes it's like 'Jeez, I should've thought of that.' And that sticks in my mind." - Respondent 30120901

"None of us like to be told what we are doing is wrong, or that we're going about it a wrong way, or we are totally off base. But to have a [coach] that is constructive and can give you some feedback is not a bad thing. They are somebody removed saying, 'Wait, there is a blind spot here that you're not seeing. '” - Respondent 2702090201

"Somebody to just be like, 'Well, this might not be the best idea' or, 'This sounds like a good idea, but here's maybe some things that you should think about before you explore it further.' It's really good to have a [coach] to run things by and to get a different perspective from somebody is like wiser and lived more of life." - Respondent 23020902

\subsection{1b Perceived needs for improvement.}

Eight participants believed there were aspects of coaching that needed improvement, all

of which related to business expertise. Coaching that provides entrepreneurs with access to business expertise helps them gain mastery experiences, where skills for coping and controlling potential threats are gained through structured meetings. Mastery experiences are the best way to increase entrepreneurial self-efficacy (Bandura, 1977), or the individual's confidence in their capabilities of performing tasks associated with entrepreneurship (Chen et al., 1998). 
However, the business expertise that was provided was perceived as needing improvement for different reasons depending on the gender of the entrepreneur. The female entrepreneurs' felt that the style used by their coach needed improvement, while the male entrepreneurs' comments on a mismatch between their coach's expertise and their venture goals.

Four female entrepreneurs commented on coaching style for the delivery business expertise:

"[My coach] really wanted to go in there and be like, 'you have to do this!' and I'd be like 'I'm not ready to do this, I want to explore this.' I don't think he necessarily knew how to guide me. He was like, 'you need to go fundraising, you need to go set up an event!' and I'm like, 'That's going to take a lot more money, and I'm not there, I want to just start-up.' He was just very overbearing." - Respondent 2020902

"I had a coach that essentially told me that I had wasted my money and was like, "why did you not reach out to me? Why did you make this decision? Next time you do something like this reach out to me first!' and I was like 'Woah, woah who the $h^{* * *}$ are you?' that pissed me off, I'll be honest, it really pissed me off for several days and as you can tell I'm still not completely over it!" - Respondent 2702090201

"The [coaches] have a perspective based on their expertise or maybe a few other industries, but sometimes I see that they are very assertive in their decisions or judgements on other industries, even though they don't have expertise in it, which is not always right." - Respondent 9020902

The coaching style is important because it impacts the effectiveness of the coaching session.

When the coach uses a style that does not resonate with the entrepreneur, they can no longer gain mastery experiences because the information is not being transferred in an effective way (St.

Jean \& Audet, 2013). The female entrepreneurs felt their coach was telling them what to do rather than listening to their needs and helping them learn.

Four male entrepreneurs indicated a need for improvement in the venture support they received because there was a mismatch between the business expertise and their venture needs:

"The [coach] they connected us to was strongly connected to the Chinese market. However, she had no insight or understanding of what we did or why we did it. So, all of her capabilities, which could've been so amazing for somebody else, had no relevance to 
us, particularly because we couldn't even enter the Chinese market. So, she could've been amazing for someone else but was connected to us." - Respondent 3020901

"I had this experience with a [coach] where we tried to work on design, but I feel like he had a vision of how the business should go, and he wasn't really understanding properly. So, I explained like, 'this is what the business is, just to make sure you understand.' Some people, it's like you kind of have to navigate them through that." - Respondent 1020301

"I have experiences with [coaches] that we come out of it more confused than when we went into it because we might not have the understanding of certain levels of corporate activities and things like that which an established company would do. So, there is no relevance, and people don't understand it for their own business." - Respondent 30120901

Male entrepreneurs identified that there is an abundance of coaches with different business expertise. Not all of the coaches' expertise aligns with the needs of the male entrepreneurs' ventures, but other coaches do fulfill their needs that are provided.

\subsection{1c Perceived as missing.}

Seven participants believed that there were things missing from their coaching experience, but there are differences between the genders in what is perceived as missing. The female entrepreneurs believed that the business expertise provided was mismatched with what their venture needed. In contrast, male entrepreneurs believed there was a lack of referrals to useful resources from their coach.

Female entrepreneurs identified that there were multiple coaches with varying business expertise, but that none of the coaches could provide the expertise that they needed for their venture. Providing business expertise improves ESE through mastery experiences (Bandura 1977), so not providing the right expertise hinders female entrepreneurs' ability to improve their ESE.

Three female entrepreneurs wanted access to different types of business expertise than what was provided by their coaches: 
"The [coaches] are not ideal because I'm building at the intersection of several disciplines, so that's really hard to find that one person that is my unicorn. I'm looking for people that are kind of professional adjacent, or expert adjacent where it's transferable." - Respondent 2702090201

"We are never taught how to manage money. They're not really teaching you about like profit, or how much you should be spending on marketing and stuff. I feel like there is a lot more in the financial area that I would love to explore." - Respondent 23020902

In contrast, three male entrepreneurs felt that their coaches did not provide adequate referrals:

"If they were to offer coaching that could provide a bit more focused connections to industry, particularly focused connections to executives, that would be hugely useful. and not only just 'how can we connect you to industry people' at the beginning, but 'how can we also help you solve your business problems and actively coach you to get access to people."” - Respondent 4020901

"I honestly think it's about having the potential of a connection to other industry professionals that could either get you funding or get you into a store or what have you." - Respondent 30120901

\subsubsection{Emotional support.}

'Emotional support' is defined here as the act of demonstrating a deeper understanding and genuine concern for the entrepreneur by providing the entrepreneurs' reassurance and building a personal relationship with them. It is comprised of three sub-dimensions: (1) compatibility- the interpersonal relationship where familiarity and trust are established; (2) shared experience - where the coach shares their personal experience with a similar problem; and (3) empathy- providing commiseration and encouragement. The comments by participants also only address emotional support as being beneficial or missing; there were not enough comments on perceived needs for improvement to draw conclusions. See Table 7 for the number of participants who commented on emotional support. 
Table 7: Emotional Support Participant Count

\begin{tabular}{|c|c|c|c|c|c|c|}
\hline \multicolumn{9}{|c|}{ Emotional Support } \\
\hline & \multicolumn{2}{|c|}{ Compatability } & \multicolumn{2}{c|}{ Shared Experience } & \multicolumn{2}{c|}{ Empathy } \\
\hline & Female & Male & Female & Male & Female & Male \\
\hline Benefit & 4 & 2 & 2 & 3 & 4 & 0 \\
\hline Needs Improvement & 1 & 0 & 1 & 1 & 1 & 0 \\
\hline Missing & 2 & 0 & 0 & 0 & 3 & 0 \\
\hline
\end{tabular}

Emotional support is perceived as being beneficial by both male and female entrepreneurs when it is provided, but only female entrepreneurs identify it as missing, while male entrepreneurs do not feel that it needs to be provided by their coach. Therefore, emotional support is perceived as being more important to female entrepreneurs than male entrepreneurs. Overall, it is an imperative aspect of coaching because it can increase ESE through three of the four pathways; physiological state of mind, vicarious learning, and social persuasion.

\subsection{2a Perceived as benefit.}

Eight participants identified aspects of emotional support as being beneficial. Both male and female entrepreneurs benefitted from compatibility and shared experience. However, more female entrepreneurs referenced compatibility than males, while more male entrepreneurs commented on shared experience than females.

Additionally, empathy was a female-only phenomenon; no male entrepreneurs recognized this as being something they benefitted from. Empathy and compatibility relate to one another because they both are about supporting the entrepreneur emotionally. However, they are separate dimensions because compatibility relates to the connection between the coach and entrepreneur that allows for honest, open discussions of any topic, including the harsh truth. In contrast, empathy is about building up the entrepreneur through positive speech and reassurance. 
All three sub-dimension of emotional support impact ESE, but through different pathways. Compatibility impacts ESE by providing a safe environment that can improve the entrepreneurs' physiological state of mind. Sharing personal experiences help entrepreneurs gain ESE because they are learning vicariously through their coach (Bandura, 1994). While empathy improves ESE through social persuasion, where the coach verbally convinces the entrepreneur that they are capable of success, reducing self-doubt (Bandura, 1994). All of these avenues are perceived as being necessary for female entrepreneurs, while male entrepreneurs benefit the most from vicarious learning.

Six participants, four females and two males commented on the familiarity and compatibility between them and their coach:

"I feel like my [coach] really tried to dip his toes into the company where he can really understand and immerse himself, which is very helpful." - Respondent 1020301

"I think it's easy to talk to my coach because he's just kind of laid-back and we kind of bonded on different levels. Like the fact that he knew the community that I come from and stuff like that, there's those common points." - Respondent 2020902

"I feel like I have built a really nice relationship with him. I almost feel like he's my father, like my business dad. I've never called him that, but I just feel like that's the relationship we have. I can go to him with almost anything and really, he just understands more of who I am. He is an all-around life coach, I would say." Respondent 23020902

Five participants, three males and two females, commented on their coaches shared experience resonating with them:

"Just the insight into their achievements, them sharing their experience with you, and it's a coaching atmosphere. They're giving you their insight and experience, and it's helpful. Other than that, you're guessing a lot, and these [coaches] have great credentials and great experience." - Respondent 26020901

"The [coach] that I'm talking to, he has talked about his experience. I like to find out about how his business is going, and he will let me know." - Respondent 4020901 
"He just has that experience to tap into. My coach has been a serial entrepreneur and a bit of a hustler. So, I kind of learning from him on how to do that. He would give me tips and tricks that he has used in the past, like tapping into the knowledge bank." Respondent 2020902

Additionally, four female participants thought that having an encouraging and empathic coach was beneficial:

"I definitely think one-on-one and longer-term is more beneficial for growth and accountability. They understand where you are and want to keep helping you grow, and the relationship can just blossom more." - Respondent 23020902

"I think it's about having a sounding board. Somebody that you know that is in your corner. Somebody who kind of has your back in a way.” - Respondent 2020902

"It helps when you have somebody that is a little bit more removed. I'm not very good at celebrating the small wins or even recognizing the small wins to be honest because I am always focused on the stuff I need to get done. So [my coach] will say, 'No, you're on the right path, you're on the right journey. This all can be recognized as that.'”Respondent 2702090201

\subsection{2b Perceived as missing.}

Only female entrepreneurs referenced emotional support as missing from their coaching experience in that they wanted it, but they expressed that they were not able to establish the connection with their coach to allow for it. Conversely, male entrepreneurs made it a point that they did not want and/or need to receive emotional support from their coaches because they sought it out from external sources.

Five female entrepreneurs expressed that emotional support was missing from their coaching experience:

“With the coaches, I don't think we've established... like we haven't been with them for a long time to rely on emotional support." - Respondent 26020902

"I don't I have one person that I reach out to regularly, so the lifecycle of the relationship just hasn't gone through that much of a variety of things to get to that emotional side." - Respondent 1020902 
"I get [one coach] who has the more business side of things, and he always brings this analytical and logical side to my questions or looking at situations. So, I just go with more business-oriented questions." - Respondent 23020902

Three males said they did not want and/or need to receive emotional support from coaches:

"I've never really asked [my coaches] for emotional support. I think the only time that happens is when other entrepreneurs will say, 'Oh my God, did you have to deal with this too' and that kind of stuff. That's about as far as that goes." - Respondent 3020901

"I don't know if I would use emotional support through the program if they offered it because I find it's just easier to get it from the people that you work with or other entrepreneurs that you see informally." - Respondent 4020901

\subsubsection{Gender sensitivity.}

Prior literature has found that gender sensitivity relates to the policies and programs that recognize and impact the differences between males and females (Kantor, 2001). 'Gender sensitivity' is defined here as an acknowledgment of gender-based differences between male and female entrepreneurs and providing coaching services accordingly. Increasing gender sensitivity can ensure that the coaching services provided do not worsen the gender-based inequalities by either ignoring the barriers for female entrepreneurs or expecting male and female entrepreneurs to function in the same way (Murray, 2005).

The female entrepreneurs perceive gender sensitivity to be missing from the coaching services within business incubators. They revealed that they face challenges that male entrepreneurs do not and are hindered by not being able to discuss the challenges they face, while also having limited representation of females in the incubator.

Five females commented on challenges they have faced being a female entrepreneur:

"It's hard for me to get up and close with [coaches] that are male. I know some of my male counterparts that run start up's end up going out for drinks with their [coaches]. If I were to do that, it would be seen as inappropriate, or people would probably ask questions. So, I tend to not have that kind of relationship, but that's where they make the most progress within their start-ups, by having those personal connections, and unfortunately, I have not had those." - Respondent 1020902 
"In getting funding from banks and stuff. I feel like there's all this, 'oh yeah, you want to do that?' but if a man went in there, then It would just be, 'oh, of course, you can definitely handle that.' Like, 'oh so you think you will make that many sales?' and I'm like, 'yeah those are my projections.' I feel that that's a whole other topic that we could just talk about, female entrepreneurship and being a minority." - Respondent 2020902

Four females felt they could not talk about their negative experiences of being a female

entrepreneur with their coaches in the incubator:

"It's not that I don't like talking about [female specific challenges], it just never comes up in conversations. You never know who is okay to talk about it or not. So that's why I don't." - Respondent 26020902

"I feel like what the incubators can do is even just talk about [female specific challenges]. There was no conversation. They wanted to increase the diversity of their applicants, and the cohort that I attended was maybe 50\% female, but how much focus did they place on making sure that the female participants get the support that they need, no there was nothing. They didn't put any special extra effort in making sure that that happened or that that was even a focus. The authenticity and true execution are still missing." - Respondent 9020902

Four females also commented on having limited access to other females in the incubator:

"We don't have strong leaders and role models to look up to in our network. There are very specific pieces of the start-up puzzle that are missing for women in particular." Respondent 9020902

“I would love a female coach, but I haven't met any yet." - Respondent 1020902

\subsubsection{Personal investment.}

'Personal investment' is the level of interest and commitment the coach puts into the

entrepreneur. Overall, personal investment is not a dimension of coaching in that it is something provided. Instead, it is a factor that can impact the delivery of emotional and venture support.

Both male and female participants felt that when their coach had a higher personal investment, it improved their coaching experience. 


\subsection{4a Perceived as benefit.}

Six entrepreneurs, three females and three males, believed that personal investment was beneficial.

"I tend to think several steps ahead. I don't just think of the here and now. So, having a [coach] that I can reach out to, where I don't have to wait until the end of the month to have a conversation, and I could just pop in and say 'Hey, I need five minutes.' That's very helpful." 2702090201

"I like the relationship I have with my coach. I know he is there when I need him, and he is always willing to have regular meetings, which I think is important." - Respondent 2020902

"I thought [personal investment] was beneficial in holding me to be accountable. Just the idea of, 'what are your goals and what are your objectives for the next week or next month' then you meet at the end of the month, and they ask if you accomplish those." Respondent 4020901

"We have a weekly meeting where the entire team meets. So, we have to send [our coach] our meeting minutes and like what we did or what the meeting was the like. It's been really good because he almost keeps us accountable in a way. It's not like in a pushy way; he is supportive, so that's been great." - Respondent 26020902

\subsection{4b Perceived needs for improvement.}

Four participants thought that the personal investment should be improved, two of which

were female and two were male:

"My second [coach] currently, I am still technically in contact with but not recently. I tried to reach out to her, and she didn't respond." - Respondent 3020901

"I've had some coaches who just disappear. My first coach had a disagreement with [incubator] and just dropped out, and I'm like, 'you had a commitment here!' so that kind of happens as well.” - Respondent 2020902

\subsection{Supplementary Analysis}

\subsubsection{Supplementary analysis procedure.}

Originally, for participant recruitment, entrepreneurs were expected to be referred to the study through the coaches that they have worked within the incubator. The intent was that both 
coaches and entrepreneurs could comment on their shared experience for what aspects of coaching were or were not beneficial. However, gaining interest in the study proved to be more difficult than anticipated, and due to time constraints, the inclusion criteria were modified to allow for coaches and entrepreneurs who had not worked collaboratively. Therefore, the coaches became part of a supplementary analysis, rather than playing an equally important role as entrepreneurs.

To gain insight into how coaches perceive their role and impact on entrepreneurs in BIs, interviews were conducted with four coaches, three male coaches and one female coach.

These four coaches were chosen for inclusion in the supplementary analysis because they were the most similar to one another according to their background information. These four participants produced over three hours of recorded responses, with interviews lasting an average of 48 minutes, or the equivalent of twelve single-spaced pages of transcribed commentary per participant. See Appendix C for more details on the coaches' analysis.

\subsubsection{Supplementary analysis findings.}

In addition to confirming venture support, emotional support, and personal investment, the coaches also identified a new factor that impacts entrepreneurial outcomes; receptiveness- the level at which an entrepreneur is willing and open to receiving support provided by coaches. Receptiveness, like personal investment, is not a dimension of coaching, but instead, is a factor that can impact the delivery of venture and emotional support.

The coaches indicated that the level of receptiveness impacts the entrepreneur's ability to benefit from the dimensions of coaching. Some coaches referenced observing a lack of receptiveness, in that there were entrepreneurs who were un-coachable because they were not receptive to the support provided by the coaches. 
Three coaches referenced a lack of receptiveness from some entrepreneurs:

"Everyone is different in terms of the approach that they will be responsive to. This issue of coachability, some people are just much more receptive and open to the type of feedback. I am sometimes just forcing them to think about things a little bit differently, or I am forcing them to face certain assumptions that they have made. The clients that are not coachable, you never actually breach that, and those are the relationships that fizzle out more quickly over time. They cycle through [coaches] and incubators because they are not in a position to be able to extract value from it." - Respondent 18010201

"Every person is unique and different in their own way, so the personalities really come out to play. Some people are good at listening, and some are not so good at listening. Some are interested in taking advice and feedback, and it's just advice and recommendations. It's not like, 'you have to do this, and this is the right way or the only way.'” - Respondent 1010601 


\section{Chapter 5: Discussion}

\subsection{Emergent Conceptual Model}

The conceptual model emerging from these findings (Figure 5) suggests that there are three dimensions of coaching that impact entrepreneurial outcomes; (1) venture supportproviding guidance and knowledge about venture start-up and growth, which incorporates three sub-dimensions (business expertise, perspective, and referral); (2) emotional supportdemonstrating a deeper understanding and genuine concern for the entrepreneur by providing reassurance and building a personal relationship, which includes three sub-dimensions (compatibility, shared experience, and empathy); (3) gender sensitivity-the acknowledgment of gender-based differences between male and female entrepreneurs and planning the coaching services accordingly.

Previous literature viewed 'gender as a variable' that influenced the strength of the relationship between coaching and entrepreneurial outcomes (Anna et al., 2000; Kalleberg \& Leicht, 1991; Shinnar, Hsu, \& Powell, 2014). In contrast, the results of this study are consistent with the 'gender as an influence' approach, where the dimensions of coaching that were perceived as being essential for personal growth and venture development differed based on gender. For males, venture support (business expertise) was more important for these outcomes, whereas female entrepreneurs benefitted more from emotional support and gender sensitivity. Thus, gender acts as an antecedent to these coaching dimensions.

The findings also suggest that entrepreneurial self-efficacy (ESE) acts as a mediator between the coaching dimensions and entrepreneurial outcomes and helps to explain why the coaching dimensions are essential. More specifically, business expertise contributes to ESE for entrepreneurs through providing mastery experiences, while compatibility contributes to ESE 
through improving the judgement of one's physiological state. Additionally, empathy helps develop ESE through providing social persuasion, and shared experiences allow for entrepreneurs to learn vicariously. Lastly, aspects of gender sensitivity impact ESE through the same pathways as emotional support; judgement of one's physiological state, social persuasion, and vicarious learning. However, business expertise was found to matter more to men entrepreneurs, while the three sub-dimensions of emotional support and gender sensitivity were perceived as being more important by women entrepreneurs for the development of ESE.

The model also suggests that referral and perspective directly influence entrepreneurial outcomes because they offer alternative avenues for gaining knowledge and create new opportunities for the entrepreneur to develop themselves or their venture.

Finally, there are two factors that moderate the influence of coaching dimensions on ESE and entrepreneurial outcomes: (1) personal investment of the coach- the level of commitment and interest the coach puts into the entrepreneur; and (2) receptiveness of the entrepreneur- the level at which an entrepreneur is willing and open to receiving support provided by coaches. The relationship between the coaching dimensions on ESE and entrepreneurial outcomes is stronger when personal investment and receptiveness are high.

It should be noted that there are two entrepreneurial outcomes included in the conceptual model; venture development and personal development. Business incubation literature identified that coaching services are intended to improve the development of new ventures and entrepreneurial skills (Hackett \& Dilts, 2004; Hausberg \& Korreck, 2018). However, this study was not able to distinguish between the impact of coaching on the entrepreneurial outcomes individually. This will be discussed further in section 6.4. 
Figure 5: Conceptual Model Linking Gender, Coaching Dimensions, and Entrepreneurial Outcomes

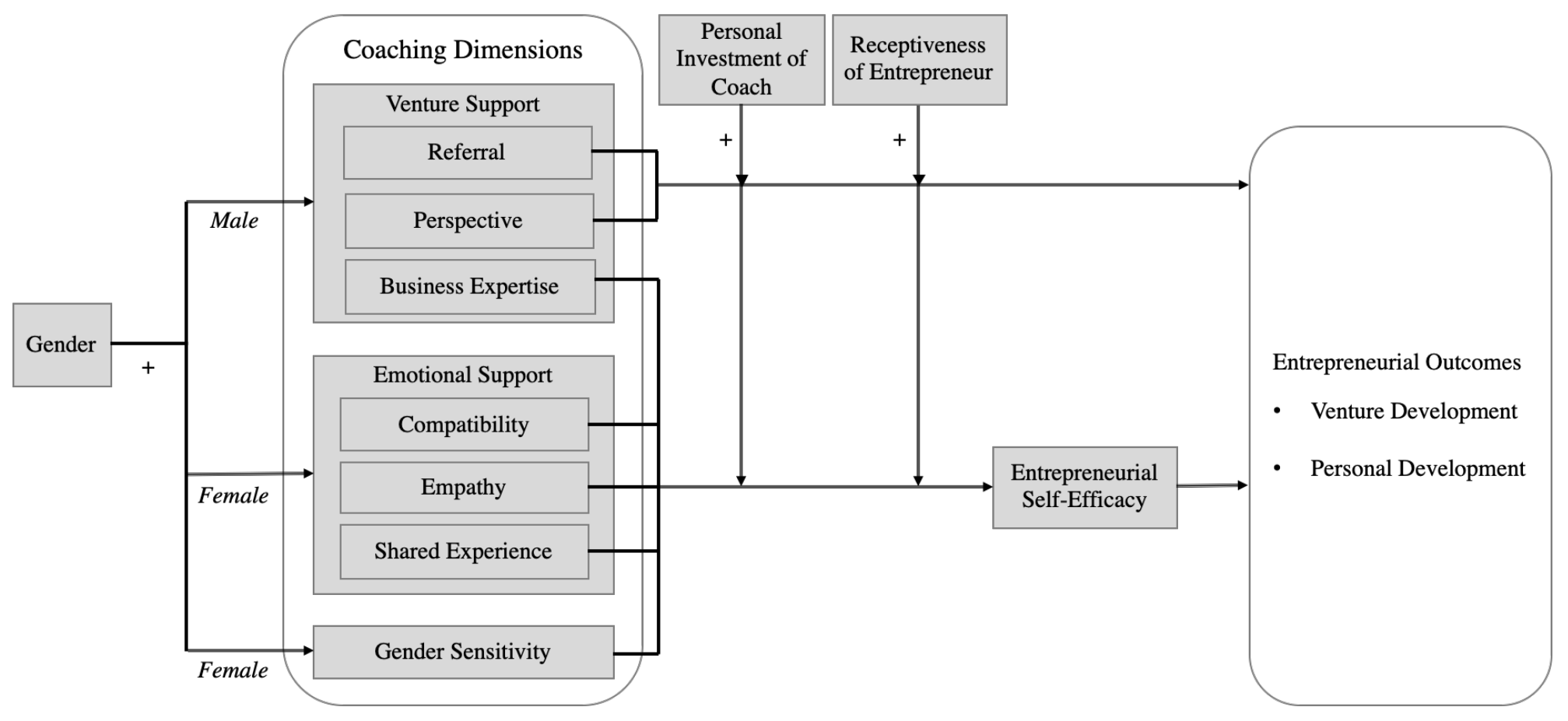

In response to the proposed research question, entrepreneurial coaching within BIs positively impacts entrepreneurial outcomes. More specifically, four of the coaching subdimensions and gender sensitivity make this contribution by directly enabling entrepreneurs to develop ESE, whereas the two other sub-dimensions offer alternative avenues for gaining knowledge or create opportunities that lead to entrepreneurial outcomes. However, there are gender-based differences in what aspects of coaching were perceived as the most helpful; male entrepreneurs favoured venture support, while female entrepreneurs valued emotional support. Also, the current coaching services appear to be missing gender sensitivity, which constrains women entrepreneurs in their pursuit of entrepreneurial outcomes.

\subsection{Coaching Dimensions}

Although the model suggests that three coaching dimensions lead to entrepreneurial outcomes, not all of the dimensions impact both male and female entrepreneurs. Using within 
and across-gender case comparisons provided rich descriptions of experiences within the particular phenomenon of entrepreneurial coaching (Eisenhardt \& Graebner, 2007). Iteration between the emerging constructs of coaching and ESE provides deeper insight into the association between the dimensions of coaching and entrepreneurial outcomes. ESE is a relevant theoretical lens for explaining these relationships because prior literature identified ESE as a critical driver for entrepreneurial behaviour (Newman et al., 2019), particularly in first-time or early-stage entrepreneurs (Miao et al., 2017) like the entrepreneurs involved in this study. Also, female entrepreneurs, in particular, have been found to have lower ESE than males (Newman et al., 2019; Zhao et al., 2005).

ESE can be developed and altered within an individual through four pathways; mastery experience, vicarious learning, social persuasion, and judgement of one's physiological state (Bandura, 1977). Similar to prior studies (St. Jean \& Audet, 2013), the findings of this study offer additional empirical evidence that supports entrepreneurial coaching as a tool to generate ESE. This study adds to the extant literature because it provides finer-grained insight about; a) how specific dimensions of coaching were associated with certain pathways for developing ESE, and b) how there are differences in the dimensions of coaching that matter to men and women entrepreneurs. Specifically, female entrepreneurs expressed that they benefitted from coaching dimensions related to all four pathways that improve ESE, while male entrepreneurs primarily benefitted from mastery experiences and vicarious learning. Additionally, three of the four pathways to gaining ESE relate directly to emotional support and gender sensitivity (judgement of physiological state, social persuasion, and vicarious learning) which was found to be more important for females than male entrepreneurs. 


\subsubsection{Venture support.}

Venture support, which includes business expertise, perspective, and referrals, was viewed as equally important for male and female entrepreneurs; both genders reaped benefits from all three sub-dimensions. Interviews with coaches confirmed that they provided venture support as a core dimension of coaching that was benefitted entrepreneurs. Broadly speaking, venture support is essential for venture development, but business expertise specifically, is also essential for personal development. Coaching on business expertise can help entrepreneurs gain ESE through mastery experiences. Mastery experiences are the best way to improve ESE because it is a self-sustaining pathway, in that once something is mastered, the entrepreneur will maintain that knowledge and expertise (Bandura, 1977; Chen et al., 1998). Consistent with the tenants of ESE, both male and female entrepreneurs valued business expertise provided by coaches. The reason they value it is because it contributes to their ESE, and that allows them to develop entrepreneurial outcomes.

However, male entrepreneurs also expressed that there were options to receive different business expertise from many coaches and that some coaches were more beneficial than others because they provided expertise that aligned with their needs. Therefore, not all coaches provided mastery experience, but male entrepreneurs were able to obtain it by moving from one coach to another. In contrast, female entrepreneurs felt that the business expertise was either poorly delivered or that they wanted access to different types of business expertise than what was provided by the available coaches. Therefore, female entrepreneurs were not able to benefit from mastery experiences to the same degree as male entrepreneurs because their coach's style limited them, or their venture needs were not met. 
Since prior research has shown that female entrepreneurs have lower ESE than male entrepreneurs (Newman et al., 2019; Zhao et al., 2005), their coaches must use a style that resonates with them to increase their mastery experiences and development of ESE. It is important to understand the expectations of all entrepreneurs and their venture needs to optimize the help that is provided to them.

Additionally, referrals and perspective were viewed as being important for both male and female entrepreneurs because they contributed to entrepreneurial outcomes through alternative ways other than ESE. Referrals provided access to resources outside of the coach's core abilities that could create opportunities for the entrepreneur or their venture. Similarly, perspective challenged the entrepreneur's thinking by providing high-level guidance that allowed them to learn about the strategic direction for their venture.

\subsubsection{Emotional support.}

Emotional support, which is comprised of compatibility, shared experience, and empathy, was found to be more important for female entrepreneurs than male entrepreneurs. Interviews with the coaches validated the findings that emotional support benefits entrepreneurs. Emotional support primarily impacts the personal development of the entrepreneurs, with each subdimension directly relating to a pathway to gain ESE. All of these pathways were perceived as being necessary for female entrepreneurs, while male entrepreneurs benefit the most from vicarious learning.

Compatibility is unique because it not only relates to the content provided by the coach, but also the interpersonal relationship between the coach and entrepreneur. When the parties have high compatibility, trust and closeness can create a stronger relationship that will make the

coaching more effective (Laukhuf \& Malone, 2015; Mansoori et al., 2019; Yang et al., 2019). 
Being in an environment where the entrepreneur feels safe can improve their physiological state of mind by reducing their stress and vulnerability, which can improve their ESE (Bandura, 1977). Compatibility was found to be beneficial for both male and female entrepreneurs, but female entrepreneurs referenced it more than the males.

Similarly, shared experience was beneficial to both male and female entrepreneurs, but more male entrepreneurs commented on the benefit of the shared experience than females. Sharing personal experiences are another tool for entrepreneurs to develop ESE because they are learning vicariously through their coach (Bandura, 1994). However, vicarious learning requires homophily between a coach and the entrepreneur in which the entrepreneur can relate their coach's success with their own ability to overcome the same challenges (Yang et al., 2019). Therefore, entrepreneurs need to be similar to their coaches so they can develop their ESE through vicarious learning. Since there were fewer female entrepreneurs who benefitted from shared experience, this could indicate that there were fewer similarities between female entrepreneurs and their coaches that limited their ability to learn vicariously.

Lastly, female entrepreneurs perceived having an empathic coach as being beneficial. Providing empathy is a way for an entrepreneur to improve their ESE through social persuasion, where the coach verbally convinces the entrepreneur that they are capable of success, reducing self-doubt (Bandura, 1994). Therefore, the findings of the study suggest that female entrepreneurs valued empathy, perhaps as a pathway to develop ESE, whereas males did not identify empathy as being important to their coaching experience.

Overall, this study found that female entrepreneurs require more emotional support than male entrepreneurs. The reasoning for why women entrepreneurs may feel the need for more emotional support was not revealed through the findings, but prior literature suggests that 
females are more sensitive to having a negative physiological state where they need greater reassurance (Manolova et al., 2012; Zhao et al., 2005). Additionally, prior research found that female entrepreneurs are more relationship-focused, having stronger relational and communal skills, which allows for a deeper understanding of their weaknesses while maintaining a willingness to improve (Gupta et al., 2019).

Although male entrepreneurs were able to benefit from emotional support when it was provided, they did not express a need for emotional support from their coaches. This male-only phenomenon could stem from the entrepreneurs following stereotypical agentic behaviour, such as having high independence and competence (Kite et al., 2008). Another factor may be because they prefer to receive emotional support from external sources, such as their friends.

\subsubsection{Gender sensitivity.}

This study defines 'gender sensitivity' as the acknowledgment of gender-based differences between male and female entrepreneurs and providing coaching services accordingly. Gender sensitivity is not about alienating female entrepreneurs, but rather creating coaching services that reduce the barriers for female entrepreneurs in ways that allow for both males and females to benefit equally. Unfortunately, the women entrepreneurs expressed that gender sensitivity was missing from the coaching services provided within BIs.

The female entrepreneurs explained gender-specific challenges they had to face, related to bias based on gender stereotypes, and that they did not feel comfortable discussing these challenges because there was no forum to discuss them within the incubator. Social role theory explains the unconscious bias that these participants have experienced because of the gender stereotypes that discredit females as being entrepreneurs (Archer, 1996; Gupta et al., 2019). These stereotypes disadvantage female entrepreneurs from the start and increase the barriers they 
have to overcome. Additionally, ESE is impacted by the physiological state of one's mind, such as high levels of stress or perceived threats (Bandura, 1977).

Lastly, it was found that female representation within the incubator was limited, particularly within coaches. Homophily between participants in the incubator plays a vital role in increasing ESE, particularly by learning vicariously (Yang et al., 2019). Additionally, having homophilic role models impacts ESE through social persuasion and vicarious learning (Bandura, 1994; Laviolette et al., 2012). Yet, female entrepreneurs lack professional role models (BarNir et al., 2011), particularly in male-dominated industries. Having a lack of female representation in an incubator hinders the female entrepreneurs because they are not able to create homophilic connections that could greatly impact their ESE.

\subsubsection{Coaching dimensions summary.}

The conceptual model emerging from this study suggests that gender acts as an antecedent to the entrepreneurial coaching dimensions because female and male entrepreneurs have different coaching needs. Although both male and female entrepreneurs perceived entrepreneurial coaching as beneficial, there were gender-based differences in the dimensions of coaching they perceived as valuable, missing or needed improvement in order to facilitate their personal and venture development.

Overall, coaching benefits entrepreneurs by contributing to their ESE, which acts as a mediator between some of the coaching dimensions and entrepreneurial outcomes. Venture support can provide mastery experiences, but women entrepreneurs might be constrained in developing this aspect of ESE by their ability to access coaches who have the business expertise they need. As a result, female entrepreneurs appear to rely more on emotional support from their coaches, specifically for improving their physiological state of mind through having a 
compatible coach that they trust, and an empathic coach who provides encouragement and social persuasion. Some female entrepreneurs also benefit from vicarious learning, where their coach shares their personal experience. However, this may be affected by the extent to which they can establish a homophilic connection (Yang et al., 2019).

The results of this study also suggest that gender sensitivity matters to female entrepreneurs but is largely missing from the current coaching services provided by BIs. When female entrepreneurs are confronting negative stereotypes, such as being treated like they are not capable entrepreneurs, then it can take a toll on their physiological state. This can be combatted by providing female entrepreneurs with a compatible coach who can create a platform to discuss and overcome these gender-specific challenges. Providing an empathetic coach who can encourage women entrepreneurs to overcome these challenges can be beneficial as well.

\subsection{Moderators}

The conceptual model emerging from this study suggests that although the support provided by coaches influences entrepreneurial outcomes, two moderators affect the strength of this relationship, the personal investment of the coach and the receptiveness of the entrepreneur. Both moderators relate to individual attributes, which when present, can positively impact the effectiveness of coaching dimensions on the entrepreneurial outcomes.

\subsubsection{Personal investment of coach.}

'Personal investment' reflects the coach's level of interest and commitment to the entrepreneur and varies depending on the individual. This was found to moderate the relationship between the coaching dimensions and entrepreneurial outcomes. Both entrepreneurs and coaches expressed this as being an important aspect of the coaching relationship, which improved the effectiveness of the support when it was provided. However, when the personal investment was 
low, the entrepreneurs were still benefitting from the coaching support, just not to the same degree as when it was provided.

\subsubsection{Receptiveness of entrepreneur.}

Receptiveness is the extent to which an entrepreneur is willing and open to receiving support provided by coaches. Receptiveness also moderates the relationship between the dimensions of coaching and entrepreneurial outcomes. This relationship was revealed through the analysis of the four coaches' interviews. When receptiveness is low, the entrepreneur is not able to benefit from the support because of their limited ability to consider or accept the information and suggestions provided by the coaches. Low receptiveness also creates a disconnect in the relationship developed between the coach and entrepreneur, therefore limiting the entrepreneurs' ability to benefit. However, when receptiveness is high, the conditions are more conducive to learning from the coach.

\subsection{Limitations}

This study explored how coaching services within BIs impact the entrepreneurial outcomes of both male and female entrepreneurs. The data provided rich insight into the dimensions of coaching from a gendered perspective. However, there were four limitations throughout the study:

First, the study provides insight into the dimension of coaching that matters to men and women entrepreneurs, but it is based on coarse-grained data collected through retrospective interviews. Deeper insight could be gained by applying methodologies that allow for real-time observation of coaching sessions and debriefing conducted over a long time period.

Second, the interview guide used for data collection did not distinguish how venture development and personal development were impacted by entrepreneurial coaching. The way the 
participants were asked about their coaching experience combined the two outcomes, so a detailed account of the impact of coaching on each outcome individually could not be obtained.

Third, the conceptual model was based on a moderately small sample size of fifteen participants, eleven entrepreneurs and four coaches, who have been involved in business incubators in the GTA. Also, due to the limited timeframe for the completion of this study, theoretical saturation cannot be confirmed. With this sample size, it is possible that the model is not generalizable to external contexts, such as other geographical locations, entrepreneurial ecosystems, or different incubators.

Fourth, the data collection and analysis processes were discussed in multiple intervals with the primary researcher's thesis advisor, but the first- and second-order coding was completed solely by the primary researcher. Therefore, although there was a rigorous process used for data collecting and analysis, there was not a team approach that is advocated in inductive research. Consequently, the findings should be interpreted with some caution.

\subsection{Implications}

Since entrepreneurship is a gendered-phenomenon that is based on masculine traits, it has become male-dominated (Brush et al., 2018; Jennings \& Brush, 2013), leading to fewer women entrepreneurs. Moreover, men and women are found to have dissimilar motivations for becoming entrepreneurs and females face additional challenges for maintaining entrepreneurial activity. Therefore, the purpose of this thesis was to gain a deeper understanding of how entrepreneurial coaching enables or constraints female and male entrepreneurs to see if both genders are similarly affected. The findings of this study have both academic and practical contributions, which will be discussed in detail throughout the next three sections; future research, managerial practice, and public policy. 


\subsubsection{Future research.}

From an academic standpoint, the findings of this study help provide deeper insight into how coaching helps female entrepreneurs in comparison to male entrepreneurs in their pursuit of new business opportunities by identifying gender-specific differences in their coaching needs. These differences are presented in the conceptual model, which provides a foundation for future theoretical and empirical research.

Although the study design allowed for within-gender and across-gender comparisons of the coaching experience for male and female entrepreneurs, future research is necessary to provide backing and extend the emergent conceptual model. Alternative deductive methodologies could provide a deeper understanding of the relationship between the dimensions of coaching for male and female entrepreneurs.

The timeline for the data collection of this study span across four months and relied on retrospective data. However, a longitudinal study could be built on the findings by following entrepreneurs and their coaches throughout their coaching experience. This methodology could collect real-time data, where the information is delivered immediately (Eisenhardt \& Graebner, 2007), to provide more granular details on the relationships that have been explored in this study.

Future research could also replicate this study's methodology in the same geographical location with different incubators to provide a deeper understanding of the relationships that were identified in the conceptual model. A replication of the study could also be performed within incubators outside of the Greater Toronto Area to assess the level of generalizability for the findings. Replication with different participants could also help expand the conceptual model by uncovering nuances in the relationship between the coaching dimensions and entrepreneurial outcomes. 
A deductive study could also further explore the distinction between coaching on the individual entrepreneurial outcomes. Future research could be directed toward operationalizing and testing the relationships discovered in this inductive study and therefore reduce limitations that stemmed from the interview guide.

Overall, the study expanded the empirical evidence provided on coaching services within BIs and suggests that future studies should continue to explore other services within BIs from a gendered perspective. Although it was outside of the scope of this study, future research could also build on the findings to address other genders (e.g. LGBT+ or non-binary) to provide a finer-grained understanding of how coaching needs are influenced by gender. Additionally, future research could explore alternative forms of diversity, such as immigrant entrepreneurs, to understand the similarities and differences in the dimensions of entrepreneurial coaching valued by different minority groups.

\subsubsection{Managerial practice.}

Through analyzing entrepreneur's perspectives of the coaching services provided in BIs, the findings reveal that there are critical differences in what males and females perceive as being beneficial for coaching. Female entrepreneurs are not able to currently benefit to the full extent as male entrepreneurs because the coaching services offered by BIs are limited in their ability to provide effective venture support to this group and are often missing emotional support, which is perceived as critical by female entrepreneurs.

Therefore, creating a one-size-fits-all model, where all entrepreneurs entering the incubator are treated the same (Kautonen et al., 2017) is not ideal. Through these findings, it is recommended that coaches provide not only venture support but also emotional support that incorporates gender sensitivity. BIs can improve their gender sensitivity by addressing gender- 
specific challenges by providing a platform where female entrepreneurs feel comfortable discussing these challenges and can brainstorm ways to overcome them. For example, female entrepreneurs could anonymously submit specific experiences or challenges they have had to overcome to the incubator staff. Then weekly meetings could be held with both the staff and female entrepreneurs that discuss the root cause and probable solutions to these challenges. Also, gender sensitivity can be improved by providing a team of coaches who can fulfill the four pathways for developing ESE since they are all viewed as being essential for women entrepreneurs.

Additionally, the outcomes of coaching services are impacted by the individual attributes of the entrepreneur. When selecting participants to be included within the incubator cohort, incubator managers should explicitly consider the entrepreneur's receptiveness to coaching as part of the selection criteria and assess it upon entry. Entrepreneurs who have low receptiveness will not be able to gain value from the resources provided by the incubator, compared to someone with high receptiveness.

Overall, this study contributes practically to incubation management by first exploring how coaching experiences help develop ESE and generate entrepreneurial outcomes, and second, through the findings highlighting the importance of design choices for developing more gender inclusive coaching services at the incubator level.

\subsubsection{Public policy.}

This study also has practical contributions to public policy because it provides insight for training programs that support women entrepreneurs specifically. By exploring the enabling and constraining factors of entrepreneurial coaching from a gendered perspective, the results suggest that some dimensions of entrepreneurial coaching influence the development of ESE, while 
others provide opportunities for learning that lead to entrepreneurial outcomes differently in male and female entrepreneurs. More specifically, female entrepreneurs need to receive not only venture support, but also emotional support, while being sensitive to gender-specific challenges.

Therefore, this study provides deeper insight into the types of support entrepreneurs may require by presenting the gender-specific needs of women entrepreneurs, so organizations like the Canadian Council for Small Business and Entrepreneurship or the City of Toronto Entrepreneurship Services can develop inclusive education and training programs for entrepreneurs. For example, public policy could implement changes in female-specific training programs by requiring emotional support to be provided through life coaching. Additionally, they could implement regulations on the gender of the staff of these organizations to ensure that female entrepreneurs can make homophilic connections with female staff members. Overall, through providing the right type of services to women entrepreneurs, the $7 \%$ gender gap between the number of men and women entrepreneurs in Canada can be reduced (Bosma et al., 2020).

Since BIs function as a part of the broader entrepreneurial ecosystem, where they receive resources such as funding from external organizations, it is important that the resources efficiently. Providing coaching services that are inclusive to all genders is important because the cost to maintain a strong pool of coaches is high. If the coaches are not benefitting all of the entrepreneurs, then time and money is being wasted. Also, entrepreneurial ventures are critical for the growth of the economy. If BIs are only benefitting male entrepreneurs, then they are limiting their output of successful start-ups.

Prior literature has also found that some BIs follow narratives that focus primarily on technology commercialization in STEM fields (Nicholls-Nixon \& Valliere, 2019). However, female entrepreneurs are often found in different industries than male entrepreneurs (Allen et al., 
2008) and are more likely to create social ventures that benefit the wider community (Buttner \& Moore, 1997; Edwards \& Field-Henry, 2002; Meyskens et al., 2011). Therefore, when developing coaching services, the chosen narrative may institute additional gender-biases that reduce the inclusivity for female entrepreneurs. The context of gender-specific needs should be considered so that coaching services are not limiting women entrepreneur's ability to develop successful ventures or make positive impacts on the broader community. 


\section{Chapter 6: Conclusion}

This study posed a question that explored the enabling and constraining factors of entrepreneurial coaching for male and female entrepreneurs. The findings revealed that there were gender-based differences in the perception of the dimensions of coaching that were beneficial, needed improvement, or were missing. A conceptual model was developed, which can be used for future studies to build upon, and suggestions were made for how to improve entrepreneurial coaching services within BIs to be inclusive to both men and women entrepreneurs. 


\section{Appendix A: Differences of Men and Women Entrepreneurs in Literature}

\begin{tabular}{|c|c|c|c|}
\hline Domains & Male Entrepreneurs & Female Entrepreneurs & References \\
\hline $\begin{array}{l}\text { Post-Secondary } \\
\text { Degree or Higher } \\
\text { (Canada Only) }\end{array}$ & $\begin{array}{c}\text { Early Stage } \\
\text { Entrepreneurs: } \\
64.7 \% \\
\\
\text { Established Business } \\
\text { Owners: } 59.3 \% \\
\end{array}$ & $\begin{array}{l}\text { Early Stage Entrepreneurs: } \\
65.8 \% \\
\text { Established Business Owners: } \\
76.2 \%\end{array}$ & $\begin{array}{c}\text { (Hughes, 2017b; Kelley et } \\
\text { al., 2017) }\end{array}$ \\
\hline $\begin{array}{l}\text { Stereo-typed } \\
\text { Behavior }\end{array}$ & Agentic & Communal & $\begin{array}{c}\text { (Brush et al., 2018; Gupta } \\
\text { et al., 2019; Kite et al., } \\
\text { 2008) }\end{array}$ \\
\hline Motivation & $\begin{array}{c}\text { Opportunity, } \\
\text { Financial and } \\
\text { Instrumental motives }\end{array}$ & $\begin{array}{c}\text { Necessity, } \\
\text { Relational and Social } \\
\text { motivations }\end{array}$ & $\begin{array}{c}\text { (Buttner \& Moore, 1997; } \\
\text { Jennings \& Brush, 2013; } \\
\text { Kelley et al., 2017) }\end{array}$ \\
\hline Push Factors & $\begin{array}{l}\text { Disagreements with } \\
\text { boss/ management }\end{array}$ & $\begin{array}{l}\text { Concern for familial and } \\
\text { household duties, need for } \\
\text { financial stability and an } \\
\text { accommodating work schedule, } \\
\text { hostile work environment, } \\
\text { frustration with advancement } \\
\text { opportunities, boredom with } \\
\text { their previous occupation }\end{array}$ & $\begin{array}{c}\text { (Brush et al., 2009; } \\
\text { Buttner \& Moore, 1997; } \\
\text { Jennings \& Brush, 2013; } \\
\text { Kelley et al., 2011) }\end{array}$ \\
\hline Pull Factors & $\begin{array}{l}\text { Improving their } \\
\text { social class, } \\
\text { increased autonomy, } \\
\text { and higher income }\end{array}$ & $\begin{array}{l}\text { Personal satisfaction (i.e. } \\
\text { seeking a challenge/ the desire } \\
\text { for self-realization and self- } \\
\text { recognition) }\end{array}$ & $\begin{array}{l}\text { (Buttner \& Moore, 1997; } \\
\text { Manolova et al., 2012) }\end{array}$ \\
\hline Success Measures & $\begin{array}{l}\text { Firm performance, } \\
\text { number of sales, } \\
\text { revenue, and job } \\
\text { creation }\end{array}$ & $\begin{array}{l}\text { Intangible view, professional } \\
\text { development, personal growth, } \\
\text { self-fulfilment, and social } \\
\text { contributions to their families } \\
\text { and the community }\end{array}$ & $\begin{array}{c}\text { (Ahl, 2006; Cooper \& } \\
\text { Artz, 1995; Powell \& } \\
\text { Eddleston, 2008) }\end{array}$ \\
\hline $\begin{array}{l}\text { Portrayal as a } \\
\text { Business Owner }\end{array}$ & $\begin{array}{l}\text { Promoted as being } \\
\text { more suitable } \\
\text { entrepreneurs }\end{array}$ & $\begin{array}{l}\text { Lower self-employment, lower } \\
\text { likeliness to be business owner } \\
\text { /manager }\end{array}$ & $\begin{array}{c}\text { (Baker et al., 1997; Brush, } \\
\text { 1998; Holmquist, 1997; } \\
\text { Hughes, 1999; Robinson } \\
\text { \& Sexton, 1994) } \\
\end{array}$ \\
\hline Firm Performance & $\begin{array}{l}\text { Superior } \\
\text { performance }\end{array}$ & $\begin{array}{l}\text { Inferior performance (lower } \\
\text { revenue, lower profit, slower } \\
\text { growth) }\end{array}$ & $\begin{array}{l}\text { (Alsos et al., 2006, 2006; } \\
\text { Bosma et al., 2004; Cliff, } \\
\text { 1998; Collins-Dodd et al., } \\
\text { 2004; Cooper et al., 1994; } \\
\text { Fischer et al., 1993; Orser } \\
\text { \& Hogarth-Scott, 2002; } \\
\text { Riding \& Swift, 1990; } \\
\text { Rosa et al., 1996; Watson } \\
\text { \& Robinson, 2003) }\end{array}$ \\
\hline
\end{tabular}




\begin{tabular}{|c|c|c|c|}
\hline Dominant Sectors & $\begin{array}{c}\text { Business services, } \\
\text { manufacturing, and } \\
\text { exporting }\end{array}$ & Personal services and retail & $\begin{array}{c}\text { Allen et al., 2008; Orser } \\
\text { et al., 2006) }\end{array}$ \\
\hline $\begin{array}{c}\text { Management } \\
\text { Styles/Strategies }\end{array}$ & $\begin{array}{c}\text { Mix of feminine and } \\
\text { masculine } \\
\text { management styles }\end{array}$ & $\begin{array}{c}\text { Mix of feminine and masculine } \\
\text { management styles } \\
\text { More likely to have home-based } \\
\text { businesses or social ventures }\end{array}$ & $\begin{array}{c}\text { Edwards \& Field-Henry, } \\
\text { (Collins-Dodd et al., 2004; } \\
\text { Eeyskens et al., } \\
\text { 2011) }\end{array}$ \\
\hline Financial Resource \\
Acquisition & $\begin{array}{c}\text { Seek VC and angel } \\
\text { investors, higher } \\
\text { funds provided, } \\
\text { provided funds at all } \\
\text { stages of the } \\
\text { company }\end{array}$ & $\begin{array}{c}\text { Lower initial funding, operate } \\
\text { with less funding, less likely to } \\
\text { utilize outside funding, less } \\
\text { likely to seek angel investors or } \\
\text { VCs, given less capital, funding } \\
\text { more early stages of company }\end{array}$ & $\begin{array}{c}\text { (Alsos et al., 2006; Carter } \\
\text { et al., 2003; Collins-Dodd } \\
\text { Robb, 2009) }\end{array}$ \\
\hline
\end{tabular}




\section{Appendix B: Interview Guide for Entrepreneurs}

1. When you entered the incubator, what process did you go through to gain a coach?

a. Was your coach assigned?

b. How long have you been working with your coach?

c. How often do you meet?

d. What triggers a coaching session?

2. Before working with your coach, how did you expect to benefit?

a. What did you expect your coach to be like?

3. Walk me through a typical meeting with your coach.

a. What do you do in your coaching sessions? What do you talk about?

4. Could you provide specific examples of how your coach has helped your personal growth or helped move your venture forward?

5. Have there been any aspects of your coaching relationship that has hindered your personal growth or the growth of your venture? Provide examples.

6. Has there been anything your coach made you do that was a waste of time or distracted you from moving your venture forward? Provide examples.

7. What has been the most important or valuable things you have gained from coaching?

a. Have you gained anything from coaching that will benefit you beyond this current venture?

b. Would you or your venture be successful if you had not had this coaching?

8. What aspects make the coaching relationship effective?

a. What aspects make the coaching relationship ineffective?

9. Describe your ideal coach.

10. For the purposes of recording and analyzing your responses to the interview questions, could you please indicate whether you are male or female? 


\section{Appendix C: Supplementary Analysis of Coaches \\ 1 Supplementary Methodology}

\subsection{Inclusion criteria}

For coaches to be included in the study, they must currently be working in the incubator on either a part-time or full-time basis and have experience working with multiple entrepreneurs who are at an early stage of their business. They must also be either a Canadian citizen or permanent resident, to reduce extraneous factors related to being a newcomer in Canada.

\subsection{Participant Recruitment}

It is unknown how many coaches were contacted through the incubator directors or personal contacts, but the primary researcher directly contacted twelve coaches. Ten coaches were recruited for the study; one through an incubator director, one through a personal contact, and eight through the direct contact from the primary researcher. Only four of those coaches were eligible to participate.

Additionally, the coaches' interview guide (see Appendix D) was pre-tested with a coach that was unrelated to the study to ensure that it addressed the key factors related to entrepreneurial coaching and asked appropriate questions. From this pre-test, it was easier to understand which probing questions were needed.

\subsection{Sample Description}

Four coaches (three males and one female) were included in this study. To identify which coaches were the best representatives for this study and ensure similarities between the participants, their background information was compared. This information was obtained through interview commentary and publicly available resources, such as LinkedIn. This 
information included their gender, incubator involvement, education, entrepreneurial experience, and non-entrepreneurial experience. See Table 8 for the background information of the coaches.

Table 8: Description of Coaches' Background

\begin{tabular}{|c|c|c|}
\hline Sex & 3 male & 1 female \\
\hline $\begin{array}{c}\text { Incubator } \\
\text { Involvement }\end{array}$ & $\begin{array}{c}3 \text { coaching in multiple } \\
\text { incubators }\end{array}$ & $\begin{array}{c}1 \text { coaching in one } \\
\text { incubator }\end{array}$ \\
\hline Education & $\begin{array}{c}3 \text { with Bachelor's } \\
\text { degree or higher }\end{array}$ & $\begin{array}{c}1 \text { without university } \\
\text { education }\end{array}$ \\
\hline $\begin{array}{c}\text { Entrepreneurial } \\
\text { Experience }\end{array}$ & $\begin{array}{c}4 \text { with prior } \\
\text { entrepreneurial } \\
\text { experience }\end{array}$ & $\begin{array}{c}\text { entrepreneurial } \\
\text { experience }\end{array}$ \\
\hline $\begin{array}{c}\text { External Work } \\
\text { Experience }\end{array}$ & $\begin{array}{c}2 \text { with five years of } \\
\text { experience }\end{array}$ & 2 with $>10$ years \\
\hline
\end{tabular}

\section{Supplementary Analysis Procedure}

Analysis for the coaches was done by hand, where the four interviews were printed and read through. They were then read through a second time, while making margin notes that related to the interview questions, much like the process for the entrepreneurs. The most significant responses were identified, and first-order codes that corresponded to the interview guide were created. Two first-order codes were identified; (1) what aspects of coaching were beneficial, in that they added value to the entrepreneur (benefit); and (2) what aspects of the relationships between the coach and the entrepreneur were perceived to be effective or ineffective at adding value to the entrepreneur (relationship effectiveness). Each interview was then first-order coded by hand.

Subsequently, continuing with a grounded theory approach, an Excel file was made that included tables of representative quotes for each interview within each first-order code. At this 
point, broad comparisons were made between the entrepreneur's interviews and the coach's interviews, which looked for similarities and differences in the emerging themes. This resulted in the creation of second-order codes for the coaches, where the dimensions of coaching and factors impacting those dimensions were identified.

The majority of the commentary from the coaches' interviews fit into the same secondorder dimensions and impacting factors that were developed by the entrepreneurs, including; venture support (business expertise, perspective, referrals), emotional support (compatibility, empathy, shared experience), and personal investment. This validates that the insights from the entrepreneurs were legitimate aspects of coaching since the same dimensions were also identified by interviewing coaches. However, one additional second-order factor that impacts the dimensions of coaching was identified; receptiveness- the level at which an entrepreneur is willing and open to receiving support provided by coaches.

The representative quotes of the first-order codes were then added to a new table that was categorized by the second-order codes. Then, a final table that counted the total number of participants per second-order code was created. These tables were then evaluated based on the most significant aspects of coaching from the coaches' perspectives.

\section{Supplementary Analysis Findings}

All four coaches identified that their coaching benefitted entrepreneurs by providing venture support, emotional support, and personal investment. These benefits align with what the entrepreneurs perceived as being valuable from coaching as well. See Table 9 for the total number of participants who referenced each second-order code. Similarly, the coaches indicated that a mismatch could occur between their business expertise and the entrepreneur's venture needs, which was also a problem that was identified in the entrepreneurs' analysis. 
Table 9: Total Coach Count per Code

\begin{tabular}{|c|c|}
\hline Dimension & $\begin{array}{c}\text { Total Number } \\
\text { of Participants }\end{array}$ \\
\hline Venture Support & 4 \\
\hline Emotional Support & 4 \\
\hline & \\
\hline Impacting Factor & $\begin{array}{l}\text { Total Number } \\
\text { of Participants }\end{array}$ \\
\hline Personal Investment & 4 \\
\hline Receptiveness & 3 \\
\hline
\end{tabular}

\subsection{Venture Support}

'Venture support' is when the coaches provide guidance and knowledge about venture start-up and growth, which includes business expertise, perspective, and referrals.

\subsubsection{Perceived as benefit.}

All four coaches agreed that venture support was beneficial for entrepreneurs. Business expertise was perceived as the most valuable aspect, while only one coach commented on the benefit of referrals.

All four coaches commented on their task-specific knowledge, or business expertise benefitted entrepreneurs:

“They'll pitch for five minutes, and then I'm like, 'hey, here's what I'm hearing, you have a good company, this is compelling, but I am missing these pieces of information. Let's get into the nitty-gritty of what deliverable will put you forward?' So, a block of text, a work in progress PDF, a draft of a deck, a list of nasty questions that you've gotten in your last pitch. What is the next thing that we need to put together that will incrementally improve the business?'” - Respondent 1010301

"It's just forcing them to focus on understanding the market and the customers in the market. Then building the product or experience around that because once they start to do that, then they should get product-market fit. Then, I can transfer like, what are some strategies that we can now implement to get this working." - Respondent 1010601 
Two of the coaches also referenced providing high-level strategic advice or perspective as benefitting entrepreneurs:

"The thing I think is most valuable that I can do for the [entrepreneurs] is encouraging them to think differently and to think about their problems in ways that they are not currently thinking about them. By seeing it differently, they realize either their own personal biases, or it helps them solve those problems in ways they wouldn't have been able to do on their own." - Respondent 18010201

"I work from a very high-level strategic marketing perspective. So, I will work with [entrepreneurs] on number one, 'what is your vision for the company? In 10 years, where do you want to be, and why?' Then I will work with [them] on the 'why,' which is [their] purpose. So, it's very high-level work that I do with them." - Respondent 1010402

\subsubsection{Perceived need for improvement.}

The coaches also believed that occasionally there was a mismatch between the venture support they provided, and the entrepreneur's venture needs. This mismatch reduced the value of the venture support overall, due to a lack of relevance with their expertise. Therefore, after identifying a mismatch, the coaches will often turn down the entrepreneur as to not waste time for either of them.

Three coaches commented on their business expertise being mismatched with the entrepreneur's venture needs:

"I don't just take any [entrepreneur]. We work with each other for two or three sessions to make sure that it's the right fit. If I feel that it's not the right fit and I can't impact their business, then you know it's bye-bye" - Response 1010402

"It's not necessarily that I'll turn an [entrepreneur] down for help; it's just that in the discovery and in the diagnosis phase, we identify bigger issues besides pitching that I am not an expert in." - Respondent 1010301

Therefore, it is important that the business expertise provided by the coaches to match what is needed by the entrepreneurs to add value. Otherwise, time and resources were wasted.

\subsection{Emotional Support}


'Emotional support' is when a coach demonstrates a deeper understanding and genuine

concern for the entrepreneur by providing reassurance and building a personal relationship with them. It includes three sub-dimensions; compatibility, empathy, and shared experience. Again, the coaches have confirmed the insights provided by the entrepreneurs about emotional support being an important dimension of coaching.

\subsubsection{Perceived as benefit.}

The coaches recognized compatibility and empathy as being the most beneficial subdimensions of emotional support for the entrepreneurs. Only one coach commented on their shared experience as being beneficial.

All four coaches illustrated that relationship compatibility was beneficial for entrepreneurs:

"We can talk shop about what they're going through regardless of what it is. That sets them at ease to help trust me, trust the process, to reach out to me when there's problems, trust my discretion if they have really difficult problems, and whatever else. Like every problem you can think of has come up at some point. It's really difficult stuff for entrepreneurs to go through sometimes, because entrepreneurship is very lonely, and so that's why coaching is so crucial." - Respondent 1010301

"The [relationship] is based on trust, so the [entrepreneurs] have to make themselves vulnerable, and I also have to be open, approachable, and not judgmental. Then we can start to get to the good stuff where we are developing that sense of personal rapport, which is not necessarily based on, 'the [coach] knows better than you' because the [entrepreneurs] are the experts in their business." - Respondent 18010201

Three coaches also commented that encouragement and empathy were beneficial for entrepreneurs:

"Sometimes overlooked, but [the biggest benefit] is just somebody to commiserate with. Just a human being, therapist style, saying like, 'entrepreneurship is so hard. I have totally been there, and that sucks.' And sometimes, just the act of providing that outlet to communicate and commiserate gives the [entrepreneurs] perseverance. Telling them, 'Hey, you're not crazy for doing this' is tremendously valuable because that adds to the resilience that they need." - Respondent 18010201

"There is a large number of high achieving entrepreneurs that come across as being very confident, but actually have a large amount of self-worth issues. What I do is help them 
be who they are and find themselves in a place that's just safe for them to grow as a person. To overcome limiting beliefs and cross the boundaries that hold them back. I helped him identify those boundaries, and then I push them until they get over it, and they grow so immensely as a person." - Respondent 1040102

\subsection{Personal investment}

'Personal investment' is the level of interest and commitment the coach puts into the entrepreneur. This dimension impacts the delivery of both venture and emotional support.

\subsubsection{Perceived as benefit.}

The coaches felt that when they had higher personal investment, there were added benefits for the entrepreneurs.

All four coaches commented on personal investment being beneficial:

"I think where you provide on-going momentum and value to the company is actually following up with the company with hands-on deliverables where they don't get to set the schedule. The thing is, knowing something is not fine is one thing, but doing something about it is very hard." - Respondent 1010301

"I will give them tasks and actual things to complete by the time we meet up the following time. Generally, I also will give them homework of some type, but not so much homework to give back to me; it's really something that is actually useful for them to use on-going." Respondent 1010601 


\section{Appendix D: Interview Guide for Coaches}

1. What process do you go through to gain an entrepreneur to coach?
a. Are the entrepreneurs assigned?
b. How often do you typically meet?
c. What triggers a coaching session?

2. Do you have a preference for any type of entrepreneur or venture that you coach?

3. Walk me through a typical meeting with your entrepreneurs.

a. What do you do in your coaching sessions? What do you talk about?

4. What do you see as your role of being a coach? What responsibilities do you have?

a. Do you change or adapt the way that you coach? Why? When?

5. How do you think entrepreneurs benefit from you coaching them? Provide specific examples of how you have helped.

6. Do you think there is anything you could improve on as a coach?

7. What is the most important aspect of the coaching relationship to you?

a. What do you think is the most important aspect for the entrepreneur?

8. What aspects make the coaching relationship effective?

a. What aspects make the coaching relationship ineffective?

9. Describe your ideal entrepreneur.

10. For the purposes of recording and analyzing your responses to the interview questions, could you please indicate whether you are male or female? 


\section{References}

Ács, Z. J., Autio, E., \& Szerb, L. (2014). National Systems of Entrepreneurship: Measurement Issues and Policy Implications. Research Policy, 43, 476-494.

Ahl, H. (2006). Why Research on Women Entrepreneurs Need New Directions.

Entrepreneurship Theory and Practice, 30(5), 595-621.

Ahmad, A. J., \& Thornberry, C. (2018). On the Structure of Business Incubators: De-coupling Issues and the Mis-alignment of Managerial Incentives. The Journal of Technology Transfer, 43(5), 1190-1212. https://doi.org/10.1007/s10961-016-9551-y

Allen, I. E., Elam, A., Langowitz, N., \& Dean, M. (2008). 2007 Report on Women and Entrepreneurship. Wellesley, MA: Babson College.

Alsos, G. A., Isaksen, E. J., \& Ljunggren, E. (2006). New Venture Financing and Sub-Sequent Business Growth in Men- and Women-Led Businesses. Entrepreneurship Theory and Practice, 30, 669-686.

Anna, A. N., Chandler, G. N., Jansen, E., \& Mero, N. P. (2000). Women Business Owners in Traditional and Non-Traditional Industries. Journal of Business Venturing, 15(3), 279303.

Archer, J. (1996). Sex Differences in Social Behavior: Are the Social Role and Evolutionary Explanations Compatible? American Psychologist, 51(9), 909-917.

Audet, J., \& Couteret, P. (2012). Coaching the Entrepreneurial: Features and Success Factors. Journal of Small Business and Enterprise Development, 19(3), 515-531.

Ayatse, F. A., Kwahar, N., \& Iyortsuun, A. S. (2017). Business Incubation Process and Firm Performance: An Empirical Review. Journal of Global Entrepreneurship Research, 7(1), 2. https://doi.org/10.1186/s40497-016-0059-6 
Babcock, L., Laschever, S., Gelfand, M., \& Small, D. (2003). Nice Girls Don’t Ask. Harvard Business Review, 81(10), 14-16.

Baker, T., Aldrish, H. E., \& Liou, N. (1997). Invisible Entrepreneurs: The Neglect of Women Business Owners by Mass Media and Scholarly Journals in the USA. Entrepreneurship and Regional Development, 9, 221-238.

Bandura, A. (1977). Self-Efficacy: Toward a Unifying Theory of Behavioral Change. Psychological Review, 84(2), 191-215.

Bandura, A. (1994). Self-Efficacy. In Encyclopedia of Human Behavior (Vol. 4, pp. 71-81). New York: Academic Press.

BarNir, A., Watson, W. E., \& Hutchins, H. M. (2011). Mediation and Moderated Mediation in the Relationship Among Role Models, Self-Efficacy, Entrepreneurial Career Intention, and Gender. Journal of Applied Social Psychology, 41(2), 270-297.

Becker-Blease, J. R., \& Sohl, J. E. (2007). Do Women-Owned Businesses have Equal Access to Venture Capital? Journal of Business Venturing, 22, 503-521.

Bergek, A., \& Norman, C. (2008). Incubator Best Practice: A Framework. Technovation, 28, 2028. https://doi.org/10.1016/j.technovation.2007.07.008

Bhatli, D. (2016). Top University Business Incubators 2015-2016. UBI Global Benchmark Report. Stockholm: UBI Global.

Bird, B., \& Brush, C. (2002). A Gendered Perspective on Organizational Creation. Entrepreneurship Theory and Practice, 26, 41-65.

Birley, S. (1989). Female Entrepreneurs: Are They Really Different? Journal of Small Business Management, 27, 32-37.

Black, N. (1989). Social Feminism. New York: Cornell University Press. 
Bosma, N., Hill, S., Ionescu-Somers, A., Kelley, D., Levie, J., \& Tarnawa, A. (2020). Global Entrepreneurship Monitor: Global Report 2019/2020 (pp. 1-232) [Report]. London, UK: London Business School.

Bosma, N., van Praag, M., Thurik, R., \& de Wit, G. (2004). The Value of Human and Social Capital Investments for the Business Performance of Startups. Small Business Economics, 23, 227-236.

Boychuk Duchscher, J. E., \& Morgan, D. (2004). Grounded Theory: Reflections on the Emergence vs. Forcing Debate. Journal of Advanced Nursing, 48(6), 605-612.

Breznitz, S. M., Clayton, P. A., Defazio, D., \& Isett, K. R. (2018). Have You Been Served? The Impact of University Entrepreneurial Support on Start-Ups' Network Formation. The Journal of Technology Transfer, 43(2), 343-367. https://doi.org/10.1007/s10961-0179565-0

Bruneel, J., Ratinho, T., Clarysse, B., \& Groen, A. (2012). The Evolution of Business Incubators: Comparing Demand and Supply of Business Incubation Services Across Different Incubator Generations. Technovation, 32(2), 110-121.

Brush, C., Carter, N., Gatewood, E., Greene, P., \& Hart, M. (2004). Clearing the Hurdles: Women Building High Growth Businesses. Englewood, NJ: Prentice Hall.

Brush, C. G. (1990). Women and Enterprise Creation. In Women, Entrepreneurship, and Economic Development (pp. 37-50). Paris: OECD.

Brush, C. G. (1992). Research on Women Business Owners: Past Trends, A New Perspective and Future Directions. Entrepreneurship Theory and Practice, 16, 45-30. 
Brush, C. G. (1998). A Resource Perspective on Women's Entrepreneurship: Research, Relevance, and Recognition. Organization for Economic Cooperation and Development (OCED), 155-168. Paris, France.

Brush, C. G., de Bruin, A., \& Welter, F. (2009). A Gender-Aware Framework for Women's Entrepreneurship. International Journal of Gender and Entrepreneurship, 1(1), 8-24.

Brush, C. G., Edelman, L. F., Manolova, T., \& Welter, F. (2018). A Gendered Look at Entrepreneurship Ecosystems. Small Business Economics, 53(2), 393-408.

Budget Plan: Canadians are Innovators. (2018, February). Retrieved from Government of Canada website: https://www.budget.gc.ca/2018/docs/plan/chap-02-en.html

Buttner, H., \& Moore, D. P. (1997). Women's Organizational Exodus to Entrepreneurship: SelfReported Motivations and Correlates with Success. Journal of Small Business Management, 35(1), 34-46.

Byrne, S. J., Farroum, S., \& Garcia, M. C. D. (2019). Role Models and Women Entrepreneurs: Entrepreneurial Superwoman Has Her Say. Journal of Small Business Management.

Cabrera, E. M., \& Mauricio, D. (2017). Factor's Affecting the Success of Women’s Entrepreneurship: A Review of Literature. International Journal of Gender and Entrepreneurship, 9(1), 31-65. https://doi.org/10.1108/IJGE-01-2016-0001

Calas, M. B., \& Smircich, L. (1996). The Woman's Point of View: Feminist Approaches to Organization Studies. In Handbook of Organization Studies (pp. 218-257). London: Sage Publications.

Carlsson, B., Braunerhjelm, P., McKelvey, M., Olofsson, C., Persson, L., \& Ylinenpaa, H. (2013). The Evolving Domain of Entrepreneurship Research. Small Business Economics, $41,913-930$. 
Carter, N., Brush, C., Greene, P., Gatewood, E., \& Hart, M. (2003). Women Entrepreneurships who Break Through to Equity Financing: The Influence of Human, Social and Financial Capital. Venture Capital Journal, 5(1), 1-28.

Chaganti, R., \& Parasuraman, S. (1996). A Study of Impacts of Gender on Business Performance and Management Patterns in Small Businesses. Entrepreneurship Theory and Practice, $21(73-75)$.

Chen, C. C., Greene, P. G., \& Crick, A. (1998). Does Entrepreneurial Self-Efficacy Distinguish Entrepreneurs From Managers? Journal of Business Venturing, 13, 295-316.

Clarysse, B., \& Bruneel, J. (2007). Nurturing and Growing Innovative Start-Ups: The Role of Policy as Integrator. $R \& D$ Management, 37(2), 139-149.

Cliff, J. E. (1998). Does One Size Fit All? Exploring the Relationship Between Attitudes Towards Growth, Gender, and Business Size. Journal of Business Venturing, 13, 523542.

Cliff, J. E., Langton, N., \& Aldrich, H. E. (2005). Walking the Talk? Gendered Rhetoric vs. Action in Small Firms. Organization Studies, 26, 61-89.

Cohen, S. L., Bingham, C. B., \& Hallen, B. J. (2018). The Role of Accelerator Designs in Mitigating Bounded Rationality in New Ventures. Administrative Science Quarterly, 64(4), 1-45.

Coleman, S., \& Kariv, D. (2013). Deconstructing Entrepreneurial Self Efficacy: A Gendered Perspective on the Impact on ESE and Community Entrepreneurial Culture on the Financial Strategies and Performance of New Firms. Venture Capital: International Journal of Entrepreneurial Finance, 16(2), 157-181. 
Coleman, S., \& Robb, A. (2012). Gender-Based Firm Performance Differences in the United States: Examining the Toles of Financial Capital and Motivations. In Global Women's Entrepreneurship Research: Diverse Settings, Questions and Approaches (pp. 75-94). Cheltenham: Edward Elgar.

Collins-Dodd, C., Gordon, I., \& Smart, C. (2004). Further Evidence on the Role of Gender in Financial Performance. Journal of Small Business Management, 42, 395-417.

Cooper, A. C., \& Artz, K. (1995). Determinants of Satisfaction of Entrepreneurship. Journal of Business Venturing, 10, 439-457.

Cooper, A. C., Gimeno-Gascon, F. J., \& Woo, C. Y. (1994). Initial Human and Financial Caital as Predictors of Performance. Journal of Business Venturing, 9, 371-395.

Creswell, J. W. (1998). Qualitative Inquiry and Research Design: Choosing Among Five Traditions (2nd ed.). Thousand Oaks, CA: Sage Publications.

Denzin, N., \& Lincoln, Y. (1994). Introduction: Entering the Field of Qualitative Research. In Handbook of Qualitative Research (pp. 1-17). Thousand Oaks, CA: Sage Publications.

Denzin, N., \& Lincoln, Y. (2018). Handbook of Qualitative Research (5th ed.). London: Sage Publications.

Eagly, A. H. (1987). Reporting Sex Differences. American Psychologist, 42(7), 756-757.

Eagly, A. H. (1997). Sex Differences in Social Behavior: A Social-Role Interpretation. American Psychologist. Retrieved from https://journals-scholarsportalinfo.ezproxy.lib.ryerson.ca/pdf/0003066x/v52i0012/1380_sdisb.xml

Edwards, L., \& Field-Henry, E. (2002). Home-Based Work and Women’s Labor Force Decisions. Journal of Labor Economics, 20, 170-200. 
Eisenhardt, K. M. (1989). Building Theories from Case Study Research. Academy of Management Review, 14, 532-550.

Eisenhardt, K. M., \& Graebner, M. E. (2007). Theory Building from Cases: Opportunities and Challenges. Academy of Management Journal, 50, 25-32.

Eisenhardt, K. M., Graebner, M. E., \& Sonenshein, S. (2016). Grand Challenges and Inductive Methods: Rigor Without Rigor Mortis. Academy of Management Journal, 59, 11131123.

Etzkowitz, H. (2002). Incubation of Incubators: Innovation as a Triple Helix of UniversityIndustry-Government Networks. Science and Public Policy, 29(2), 115-128.

Fairlie, R. W., \& Robb, A. M. (2009). Gender Differences in Business Performance: Evidence from the Characteristics of Business Owners Survey. Small Business Economics, 33, $375-395$.

Fischer, E. M., Reuber, R. A., \& Dyke, L. S. (1993). A Theoretical Overview and Extension of Research on Sex, Gender, and Entrepreneurship. Journal of Business Venturing, 8(2), $151-168$.

Fletcher, D. E. (2006). Entrepreneurial Processes and the Social Construction of Opportunity. Entrepreneurship and Regional Development, 421-440. https://doi.org/10.1080/08985620600861105

Foss, L., Henry, C., Ahl, H., \& Mikalsen, G. H. (2018). Women's Entrepreneurship Policy Research: A 30 Year Review of the Evidence. Small Business Economics, 53(2), 409429. 
Foss, Lene. (2010). Research on Entrepreneur Networks: The Case for a Constructionist Feminist Theory Perspective. International Journal of Gender and Entrepreneurship, 2(1), 83-102.

Galbraith, B., McAdam, R., \& Cross, S. E. (2019). The Evolution of the Incubator: Past, Present, and Future. IEEE Transactions on Engineering Management.

Gilligan, C. (1982). In a Different Voice. Cambridge: Harvard University Press.

Gioia, D. A., Corley, K. G., \& Hamilton, A. L. (2013). Seeking Qualitative Rigor in Inductive Research Notes on the Gioia Methodology. Organizational Research Methods, 16(1), $15-31$.

Glaser, G. B. (1998). Doing Grounded Theory: Issues and Discussions. Mill Valley, CA: Sociology Press.

Glaser, G. B., \& Strauss, A. L. (1967). The Discovery of Grounded Theory. New York: Aldine de Gruyter.

Good, M., Knockaert, M., Soppe, B., \& Wright, M. (2019). The Technology Transfer Ecosystem in Academia. An Organizational Design Perspective. Technovation, 82, 35-50.

Greene, P., Brush, C., Hart, M., \& Saparito, P. (2001). Exploration of the Venture Capital Industry: Is Gender and Issue? Venture Capital Journal, 3(1), 63-83.

Grekou, D., Li, J., \& Liu, H. (2018, September). Women-Owned Enterprises in Canada [Government]. Retrieved from Statistics Canada website: https://www150.statcan.gc.ca/n1/pub/11-626-x/11-626-x2018083-eng.htm

Grimaldi, R., \& Grandi, A. (2005). Business Incubators and New Venture Creation: An Assessment of Incubating Models. Technovation, 25(2), 111-121. https://doi.org/10.1016/S0166-4972(03)00076-2 
Guba, E. G. (1981). Criteria for Assessing the Trustworthiness and Naturalistic Inquiries. ECTJ, 29(2), 75-91.

Guest, G., Bunce, A., \& Johnson, L. (2006). How Many Interviews Are Enough? An Experiment with Data Saturation and Variability. Field Methods, 18(1), 59-82.

Gupta, V. K., Weiland, A. M., \& Turban, D. B. (2019). Gender Characterizations in Entrepreneurship: A Multi-Level Investigation of Sex-Role Stereotypes about HighGrowth, Commercial, and Social Entrepreneurs. Journal of Small Business Management, 57(1), 131-153.

Hackett, S. M., \& Dilts, D. M. (2004). A Systematic Review of Business Incubation Research. The Journal of Technology Transfer, 29(1), 55-82.

Harding, S. (1987). Feminism and Methodology. Open University Press.

Harper-Anderson, E., \& Lewis, D. A. (2018). What Makes Business Incubation Work? Measuring the Influence of Incubator Quality and Regional Capacity on Incubator Outcomes. Economic Development Quarterly, 32(1), 60-77.

Hausberg, J. P., \& Korreck, S. (2018). Business Incubators and Accelerators: A Co-Citation Analysis-Based, Systematic Literature Review. The Journal of Technology Transfer, 45(2), 151-176. https://doi.org/10.1007/s10961-018-9651-y

Heilman, M. E., Wallen, A. S., Fuchs, D., \& Tamkins, M. M. (2004). Penalties for Success: Reactions to Women Who Succeed at Male Gender-Typed Tasks. Journal of Applied Psychology, 89, 416-427.

Henry, C., Foss, L., \& Ahl, H. (2016). Gender and Entrepreneurship Research: A Review of Methodological Approaches. International Small Business Journal, 34(3), 217-241. 
Heydebreck, P., Klofsten, M., \& Maier, J. C. (2000). Innovation Support for New TechnologyBased Firms: The Swedish Teknopol Approach. R\&D Management, 30(1).

Hisrich, R. D., \& Brush, C. G. (1983). The Woman Entrepreneur: Implications of Family, Education, and Occupation. In Frontiers of Entrepreneurship Research-Proceedings of the Babson Conference on Entrepreneurship. Wellesley, MA: Babson College.

Holmquist, C. (1997). The Other Side of the Coin or Another Coin? Women's Entrepreneurship as a Complement or an Alternative? Entrepreneurship and Regional Development, 9, $179-182$.

Holton, J. A. (2010). The Coding Process and Its Challenges. The Grounded Theory Review, $9(1), 21-40$.

Hooks, B. (2000). Feminist Theory: From Margin to Center. Pluto Press.

Hoskisson, R. E., Covin, J., Volberda, H. W., \& Johnson, R. A. (2011). Revitalizing Entrepreneurship: The Search for New Research Opportunities. Journal of Management Studies, 48(6), 1141-1168. https://doi.org/10.1111/j.1467-6486.2010.00997.x

Hsu, D. K., Shinnar, R. S., \& Powell, B. C. (2014). Expectancy Theory and Entrepreneurial Motivation: A Longitudinal Examination of the Role of Entrepreneurship Education. Journal of Business and Entrepreneurship, Suppl., 26(1), 121-140.

Huber, G. P. (1985). Temporal Stability and Response-Order Biases in Participant Descriptions of Organizational Decisions. Academy of Management Journal, 28, 943-950.

Hughes, K. D. (1999). Gender and Self-Employment in Canada: Assessing Trends and Policy Implications (CPRN Study No. W/04). Ottawa, ON: Canadian Policy Research Networks. 
Hughes, K. D. (2017a). GEM Canada Report on Women's Entrepreneurship. Alberta: University of Alberta.

Hughes, K. D. (2017b). Global Entrepreneurship Monitor Canada 2015/16 Report on Women's Entrepreneurship. Alberta: University of Alberta.

Jennings, J. E., \& Brush, C. G. (2013). Research on Women Entrepreneurs: Challenges to (and from) the Broader Entrepreneurship Literature? The Academy of Management Annals, $7(1), 663-715$.

Jennings, J. E., \& McDougald, M. S. (2007). Work-Family Interface Experiences and Coping Strategies: Implications for Entrepreneurship Research and Practice. Academy of Management Review, 32(3), 747-760.

Kalleberg, A. L., \& Leicht, K. T. (1991). Gender and Organizational Performance: Determinants of Small Business Survival and Success. Academy of Management Journal, 34(1), 136161.

Kantor, P. (2001). Promoting Women's Entrepreneurship Development based on Good Practice Programmes: Some Experiences from the North to the South. Retrieved from International Labour Organization website: http://www.ilo.org/public/libdoc/ilo/2001/101B09_39_engl.pdf

Kautonen, M., Pugh, R., \& Raunio, M. (2017). Transformation of Regional Innovation Policies: From 'Traditional' to 'Next Generation' Models of Incubation. European Planning Studies, 25(4), 620-637. https://doi.org/10.1080/09654313.2017.1281228

Kelley, D. J., Baumer, B. S., Brush, C. G., Greene, P. G., Mahdavi, M., Cole, M. M. M., ... Heavlow, R. (2017). Global Entrepreneurship Monitor: Women’s Entrepreneurship 2016/2017 Report. Global Entrepreneurship Research Association, 93. 
Kelley, D. J., Brush, C. G., Greene, P. G., \& Litovsky, Y. (2011). The Global Entrepreneurship Monitor: 2010 Women's Report. Wellesley, MA: Babson College \& GERA.

Kirzner, I. M. (1997). Entrepreneurial Discovery and the Competitive Market Process: An Austrian Approach. Journal of Economic Literature, 35, 60-85.

Kite, M. E., Deaux, K., \& Haines, E. L. (2008). Psychology of Women: A Handbook of Issues and Theories (2nd ed.). Praeger Publishers.

Klonaridis, R., \& de Klerk, N. (2017). Start-Up and Established Organisations' Requirements From University Business Incubators. International Journal of Business and Management Studies, 9(2), 14.

Langowitz, N., \& Minniti, M. (2007). The Entrepreneurial Propensity of Women. Entrepreneurship Theory and Practice, 31(3), 341-364.

Lasrado, V., Sivo, S., Ford, C., O-Neal, T., \& Garibay, I. (2016). Do Graduated University Incubator Firms Benefit from their Relationship with University Incubators? Journal of Technology Transfer, 41(2), 205-219.

Laukhuf, R. L., \& Malone, T. A. (2015). Women Entrepreneurs Need Mentors. International Journal of Evidence Based Coaching and Mentoring, 13(1), 70-85.

Laviolette, E. M., Lefebvre, M. R., \& Brunel, O. (2012). The Impact of Story Bound Entrepreneurial Role Models on Self-Efficacy and Entrepreneurial Intention. Internal Journal of Entrepreneurial Behaviour \& Research, 18(6), 720-742.

Lewis, K. V. (2015). Enacting Entrepreneurship and Leadership: A Longitudinal Exploration of Gendered Identity Work. Journal of Small Business Management, 53(3). 
Manolova, T. S., Brush, C. G., Edelman, L. F., \& Shaver, K. G. (2012). One Size Does Not Fit All: Entrepreneurial Expectancies and Growth Intentions of US Women and Men Nascent Entrepreneurs. Entrepreneurship and Regional Development, 24(1-2), 7-27.

Mansoori, Y., Karlsson, T., \& Lundqvist, M. (2019). The Influence of the Lean Startup Methodology on Entrepreneur-Coach Relationship in the Context of a Startup Accelerator. Technovation, 85, 37-47.

Marlow, S., \& McAdam, M. (2012). Analyzing the Influence of Gender Upon High Technology Venturing Within the Context of Business Incubation. Entrepreneurship Theory and Practice, 36(4), 655-676.

Marlow, Susan. (2002). Women and Self-Employment: A Part of or Apart From Theoretical Construct? Entrepreneurship and Innovation, 2(2), 83-91.

Maxwell, J. A. (1992). Understanding and Validity in Qualitative Research. Harvard Educational Review, 62(3), 279-300.

Meunier, F., Krylova, Y., \& Ramalho, R. (2017, November). Women's Entrepreneurship: How to Measure the Gap Between New Female and Male Entrepreneurs? World Bank Group.

Meyskens, M., Brush, C., \& Allen, E. (2011). Human Capital and Hybrid Ventures. In Social and Sustainable Entrepreneurship: Advances in Firm Emergence and Growth (pp. 5172). Bingley: Emerald.

Mian, S., Lamine, W., \& Fayolle, A. (2016). Technology Business Incubation: An Overview of the State of Knowledge. Technovation, 50-51, 1-12. https://doi.org/10.1016/j.technovation.2016.02.005 
Miao, C., Qian, S., \& Ma, D. (2017). The Relationship between Entrepreneurial Self-Efficacy and Firm Performance: A Meta-Analysis of Main and Moderator Effects. Journal of Small Business Management, 55(1), 87-107.

Minniti, M. (2010). Female Entrepreneurship and Economic Activity. European Journal of Development Research, 22, 294-312. https://doi.org/10.1057/ejdr.2010.18

Minniti, M., \& Arenius, P. (2003). Women in Entrepreneurship. The Entrepreneurial Advantage of Nations. Presented at the First Annual Global Entrepreneurship Symposium, United Nations Headquarters.

Mueller, S. L., \& Dato-On, M. C. (2008). Gender-Role Orientation as a Determinant of Entrepreneurial Self-Efficacy. Journal of Developmental Entrepreneurship, 13(1), 3-20.

Murray, U. (2005). Promoting Gender-Sensitive Entrepreneurship via Microfinance Institutions. Food and Agriculture Organization of the United Nations (FAO). Gender and Population Division. Retrieved from https://cdn.atria.nl/epublications/2005/Promoting_gendersensitive_entrepreneurship_via_ microfinan.pdf

Neergaard, H., Frederiksen, S. H., \& Marlow, S. (2011). The Emperor's New Clothes: Rendering A Feminist Theory of Entrepreneurship Visible. Presented at the 56th ICSB Conference, Stockholm.

Newman, A., Obschonka, M., Schwarz, S., Cohen, M., \& Nielsen, I. (2019). Entrepreneurial Self-Efficacy: A Systematic Review of the Literature on its Theoretical Foundations, Measurement, Antecedents, and Outcomes, and an Agenda for Future Research. Journal of Vocational Behavior, 110, 402-419. 
Nicholls-Nixon, C., \& Valliere, D. (2019). A Framework for Exploring Heterogeneity in University Business Incubators. Entrepreneurship Research Journal. https://doi.org/10.1515/erj-2018-0190

Nicholls-Nixon, C., Valliere, D., \& Hassannezhad, Z. (2018, September). A Typology of University Business Incubators: Implications for Research and Practice. 22, 535-543. Academic Conferences International Limited.

Nilsson, P. (1997). Business Counselling Services Directed Towards Female EntrepreneursSome Legitimacy Dilemmas. Entrepreneurship and Regional Development, 9(3), 239258.

Noble, B. (1986). A Sense of Self. Venture, 34-36.

Noble, H., \& Smith, J. (2015). Issues of Validity and Reliability in Qualitative Research. Evidence Based Nursing, 18(2), 34-35.

Orser, B., \& Hogarth-Scott, S. (2002). Opting for Growth: Gender Dimensions for Choosing Enterprise Development. Canadian Journal of Administrative Sciences, 19, 284-300.

Orser, B., Riding, A. L., \& Manley, K. (2006). Women Entrepreneurs and Financial Capital. Entrepreneurship Theory and Practice, 30, 643-665.

Patton, M. Q. (1999). Enhancing the Quality and Credibility of Qualitative Analysis. Health Services Research, 34(5), 1189-1208.

Peters, L., Rice, M., \& Sundararajan, M. (2004). The Role of Incubators in the Entrepreneurial Process. Journal of Technology Transfer, 29, 83-91.

Powell, G. N., \& Eddleston, K. A. (2008). The Paradox of the Contented Female Business Owner. Journal of Vocational Behavior, 73, 24-36. 
PwC. (2018). Women Entrepreneurship in Canada Report. Retrieved from Women

Entrepreneurs Saskatchewan website: https://wesk.ca/wpcontent/uploads/2018/10/WESK-Report-Oct.-15-2018-PwC-1.pdf

Riding, A. L., \& Swift, C. S. (1990). Women Business Owners and Terms of Credit; Some Empirical Findings of the Canadian Experience. Journal of Business Venturing, 5(327340).

Robinson, P. R., \& Sexton, E. A. (1994). The Effect of Education and Experience on SelfEmployment Success. Journal of Business Venturing, 0, 141-156.

Rosa, P., Carter, S., \& Hamilton, D. (1996). Gender as a Determinant of Small Business Performance: Insight from a British Study. Small Business Economics, 8, 463-478.

Salem, A. B., \& Lakhal, L. (2018). Entrepreneurial Coaching: How to be Modeled and Measured? Journal of Management Development, 37(1), 88-100.

Sandelowski, M. (1993). Rigor or Rigor Mortis: The Problem or Rigor in Qualitative Research Revisited. Advances in Nursing Science, 16(2), 1-8.

Sandström, C., Wennberg, K., Wallin, M. W., \& Zherlygina, Y. (2018). Public Policy for Academic Entrepreneurship Initiatives: A Review and Critical Discussion. The Journal of Technology Transfer , 43(5), 1232-1256. https://doi.org/10.1007/s10961-016-9536-x

Schein, V. E. (2001). A Global Look at Psychological Barriers to Women's Progress in Management. Journal of Social Issues, 57, 675-688.

Schermerhorn, J., Bachrach, D., \& Wright, B. (2018). Management (4th ed.). John Wiley \& Sons Inc Canada, Ltd.

Schumpeter, J. A. (1934). The Theory of Economic Development (English ed.). Cambridge, MA: Harvard University Press. 
Shabbir, A., \& DiGregorio, S. (1996). An Examination of the Relationship Between Women's Personal Goals and Structural Factors Influencing Their Decision to Start a Business: The Case of Pakistan. Journal of Business Venturing, 11, 507-529.

Shane, S., \& Venkataraman, S. (2000). The Promise of Entrepreneurship as a Field of Research. Academy of Management Review, 25(1), 217-236.

Shapero, A., \& Sokol, L. (1982). The Social Dimensions of Entrepreneurship. In The Encyclopedia of Entrepreneurship (pp. 72-90). Englewood Cliffs, NJ: Prentice Hall.

Shinnar, R. S., Hsu, D. K., \& Powell, B. C. (2014). Self-Efficacy, Entrepreneurial Intentions, and Gender: Assessing the Impact of Entrepreneurial Education Longitudinally. The International Journal of Management Education, 12(3), 561-570.

Simpson, M. (2018, October). Women Make Up One Third of Canadian Entrepreneurs, But Not in Tech Industry [News]. Retrieved from IT Business website: https://www.itbusiness.ca/news/women-make-up-one-third-of-canadian-entrepreneursbut-not-in-tech-industry/105893

St. Jean, E., \& Audet, J. (2013). The Effect of Mentor Intervention Style in Novice Entrepreneur Mentoring Relationships. Mentoring \& Tutoring: Partnership in Learning, 21(1), 96119.

St. Jean, E., \& Mathieu, C. (2015). Developing Attitudes Toward an Entrepreneurial Career Through Mentoring: The Mediating Role of Entrepreneurial Self-Efficacy. Journal of Career Development, 42(4), 325-338.

Stevenson, L. A. (1986). Against All Odds: The Entrepreneurship of Women. Journal of Small Business Management, 24(4), 30-36. 
Stevenson, L. A. (1990). Some Methodological Problems Associated with Researching Women Entrepreneurs. Journal of Business Ethics, 9(4-5), 439-446.

Sweida, G. L., \& Woods, J. A. (2015). Comparing the Development of Entrepreneurial SelfEfficacy of Female Entrepreneurs in Male- and Female-Dominated Industries. Journal of Developmental Entrepreneurship, 20(3), 1-20.

van der Vyver, J., \& van der Vyver, C. (2017). Identifying the Nature of Participatory Communication Between Stakeholders of a University Incubator. International Journal of Business and Management Studies, 9(2), 16.

von Zedtwitz, M. (2003). Classification and Management of Incubators: Aligning Strategic Objectives and Competitive Scope for New Business Facilitation. International Journal Entrepreneurship and Innovation Management, 3(1-2), 176-196.

Watson, J. (2002). Comparing the Performance of Male- and Female-Controlled Businesses: Relating Outputs to Inputs. Entrepreneurship Theory and Practice, 26, 91-100.

Watson, J., \& Robinson, S. (2003). Adjusting for Risk in Comparing the Performances of Maleand Female-Controlled SMEs. Journal of Business Venturing, 18, 773-788.

Wicker, A. W., \& King, J. C. (1989). Employment, Ownership, and Survival in Microbusiness: A Study of New Retail and Service Establishments. Small Business Economics, 1(2), $137-152$.

Yang, S., Kher, R., \& Newbert, S. (2019). What Signals Matter for Social Startups? It Depends: The Influence of Gender Role Congruency on Social Impact Accelerator Selection Decisions. Journal of Business Venturing, 35(2). https://doi.org/10.1016/j.jbusvent.2019.03.001 
Yin, R. K. (2003). Case Study Research: Design and Methods (3rd ed.). Thousand Oaks, CA: Sage Publications.

Zhao, H., Seibert, S. E., \& Hills, G. E. (2005). The Mediating Role of Self-Efficacy in the Development of Entrepreneurial Intentions. Journal of Applied Psychology, 90(6), 12651272. 